\title{
Individually tailored internet-based cognitive behavioural therapy for anxiety disorders
}

\author{
Lise Bergman Nordgren
}

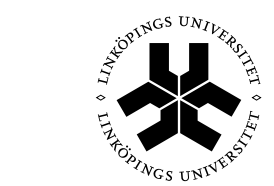

Linköping University

Linköping Studies in Arts and Science No. 598

Linköping Studies in Behavioural Science No. 180

Linköping University

Department of Behavioural Sciences and Learning

Linköping 2013 
At the Faculty of Arts and Science at Linköping University, research and doctoral studies are carried out within broad problem areas. Research is organized in interdisciplinary research environments and doctoral studies mainly in graduate schools. Jointly, they publish the series Linköping Studies in Arts and Science. This thesis comes from the Department of Psychology at the Department of Behavioural Sciences and Learning.

Distributed by:

Department of Behavioural Sciences and Learning Linköping University

58183 Linköping

\section{Lise Bergman Nordgren}

Individually tailored internet-based cognitive behavioural therapy for anxiety disorders

\section{Upplaga 1:1}

ISBN 978-91-7519-459-2

ISSN 0282-9800

ISSN 1654-2029

CLise Bergman Nordgren

Department of Behavioural Sciences and Learning, 2013

Printed by: LiU-tryck, Linköping 2013

All previously published articles were reproduced with permission from the publisher. 
It's hard to remember that this day will never come again. That the time is now and the place is here and that there are no second chances at a single moment.

Jeanette Winterson, The Passion 



\section{ABSTRACT}

Fear is an innate emotion and an adaptive response to provide protection from potential harm. When fear is excessive and out of proportion in relation to the confronted situation, it can lead to the development of an anxiety disorder. Many individuals feel anxious at some point, but not all experience clinical anxiety or meet the diagnostic criteria of an anxiety disorder. Still, anxiety disorders are the most prevalent form of psychiatric disorder in the general population. More often than not people suffering from one anxiety disorder also present other psychiatric conditions. As of today, cognitive and behavioural treatments have been tested and found to positively affect anxiety disorders, making them the treatment of choice. Nevertheless, many patients do not seek or receive adequate treatment.

One common critique of the research trials from which the recommendations for treatments stem is the use of a single protocol targeting only one diagnosis. This is because many people suffer from comorbidities. Another problem connected to the recommendation that cognitive behavioural therapy (CBT) should be the treatment of choice for anxiety disorders is the lack of therapists with adequate training. One possible way of dealing both with the shortcoming of therapists and making CBT more accessible is the use of the Internet. Internet-based CBT (ICBT) has been tested in numerous trials during the last 15 years, showing positive outcomes for a large variety of disorders. Many ICBT trials also make use of a single protocol. Another way of dealing with comorbidities might be to tailor the treatment to let characteristics and preferences of the patient guide the design of the protocol. Little is known about possible effects of tailoring the ICBT, the effects of therapeutic relationships in ICBT, and the effectiveness and cost-effectiveness of these treatments. This thesis is based on three studies on two separate randomized controlled trials (RCTs) using the same set of modules accessible for the tailored protocol.

Study I was an RCT investigating treatment effects up to two-year after completion, showing favourable outcomes of the treatment in a 
self-recruited sample at all measure points. Study II was a secondary analysis exploring possible relations between working alliance and treatment outcome for participants in the treatment group recruited for Study I indicating that working alliance predict outcome in this tailored treatment.

The second RCT was an effectiveness trial (Study III) analysing treatment effects and cost-effectiveness of the treatment up to one year post treatment in a primary-care population. This study showed positive treatment effects both regarding symptom reduction and cost-effectiveness, and that effects were sustained at one year post treatment. Conclusions drawn from these studies are that individually tailored ICBT seems to be a feasible approach for patients with anxiety disorders regardless of comorbidities, and a responsible choice in terms of societal costs.

Keywords: Anxiety, anxiety disorders, comorbidities, individually tailored Internet-based cognitive behavioural therapy, primary care, effectiveness, cost-effectiveness, working alliance, follow-up, longterm follow-up 


\section{EMPIRICAL STUDIES}

The thesis is based on the following original research papers, which are referred to in the text by their roman numerals:

I. Carlbring, P., Maurin, L., Törngren, C., Linna, E., Eriksson, T., Sparthan, E., Strååt, M., Marquez von Hage, C., Bergman Nordgren, L. \& Andersson, G. (2011). Individually-tailored, Internet-based treatment for anxiety disorders: A randomized controlled trial. Behaviour Research and Therapy. 49, 18-24.

II. Bergman Nordgren, L., Carlbring, P., Linna, E., \& Andersson, G. (2013). Role of the working alliance on treatment outcome in tailored Internet-based cognitive behavioural therapy for anxiety disorders: Randomized controlled pilot trial. Journal of Medical and Internet Research Research Protocols. 2(1):e4.

III. Bergman Nordgren, L., Hedman, E., Etienne, J., Bodin J., Kadowaki, Å., Eriksson, S., Lindkvist, E., Andersson, G., \& Carlbring, P. (2013). Effectiveness and costeffectiveness of individually tailored Internet-delivered cognitive behavior therapy for anxiety disorders in a primary care population: A randomized controlled trial. Unpublished manuscript. 


\section{TABLE OF CONTENTS}

BACKGROUND $\quad 8$

Introduction 8

Anxiety disorders 9

Fear and anxiety 9

Different forms of anxiety disorder 10

Agoraphobia without history of panic disorder 11

Panic disorder with or without agoraphobia $\quad 12$

Social phobia $\quad 13$

Generalized anxiety disorder $\quad 14$

Anxiety disorder not otherwise specified $\quad 14$

Natural course $\quad 14$

Comorbidity $\quad 15$

A cognitive behavioural model of anxiety 16

Psychological treatments of anxiety disorders 18

Cognitive behavioural therapy 19

Internet-based cognitive behavioural therapy 21

Adherence and drop-out $\quad 22$

Single protocols 23

Why tailor the treatment? 26

Working alliance $\quad 27$

Cost-effectiveness 28

Enduring effects $\quad 29$

Enduring effects of $C B T$ and ICBT 30

Anxiety disorders and their treatment in primary-care $\quad 31$

Possible ways to implement evidence-based treatments in primary care 32

EMPIRICAL STUDIES 34

Study I. Individually tailored, Internet-based treatment for anxiety disorders: A randomized controlled trial 35

Aim $\quad 35$

Methods $\quad 35$

Results and brief discussion $\quad 37$ 
Study II. Role of the working alliance on treatment outcome in tailored Internet-based cognitive behavioural therapy for anxiety disorders: Randomized controlled pilot trial $\quad 38$

Aim

Methods

Results and brief discussion

Study III. Effectiveness and cost-effectiveness of individually tailored Internet-delivered cognitive behaviour therapy for anxiety disorders in a primary-care population: A randomized controlled trial

Aim

Methods

Results and brief discussion

GENERAL DISCUSSION

Main findings and conclusions

Why the good results in ICBT?

Representativity of the samples

Drop-out rates

Comparing single and tailored protocols $\quad 48$

Enduring effects of the tailored protocol 49

Limitations

Future directions

REFERENCES 


\section{ABBREVIATIONS}

\section{BAI}

CBT

CEA

CORE-OM

CS

CR

DASS-21

DSM-IV

DSM-5

GDP

GAD-7

ICBT

ICER

MADRS-S

NAT

NICE

NS

QALY

QOLI

RCT

SCID-I

SAD PERSONS

SBU
Beck Anxiety Inventory

Cognitive Behaviour Therapy

Cost-Effectiveness Analysis

Clinical Outcomes in Routine Evaluation-Outcome Measure

Conditioned Stimuli

Conditioned Response

Depression Anxiety Stress Scale-21 item

Diagnostic and Statistical Manual of

Mental Disorders, 4th edition

Diagnostic and Statistical Manual of

Mental Disorders, 5th edition

Gross Domestic Product

Generalized Anxiety Disorder 7-item

scale

Internet-based Cognitive Behavioural

Therapy

Incremental Cost-Effectiveness Ratio

Montgomery Åsberg Depression Rating

Scale Self-Report

Negative Automatic Thoughts

the National Institute for Clinical Excel-

lence

Neutral Stimulus

Quality-Adjusted Life Years

Quality of Life Inventory

Randomized controlled trial

Structured Clinical Interview for DSM-

IV axis I disorders

Sex, Age, Depression, Previous attempt, Ethanol abuse, Rational thinking loss, Social supports lacking, Organized plan, No spouse, Sickness

Swedish Council on Health Technology Assessment 
SEK

TIC-P

USD

UCS

UCR

WAI
Swedish Krona

Trimbos and Institute of Medical Technology Assessment Questionnaire on Costs Associated with Psychiatric Illness United States Dollar

Unconditioned Stimulus

Unconditioned Reflex

Working Alliance Inventory 


\title{
BACKGROUND
}

\author{
Introduction
}

Anxiety disorders are the most prevalent psychiatric conditions in the general population, with a lifetime prevalence of almost $29 \%$ (Kessler, Berglund, Demler, Jin, \& Walters, 2005). In Europe the estimated 12 -month prevalence is nearly $17 \%$, meaning that 72 million Europeans are affected by one or more anxiety disorders (Alonso et al., 2004a; Wittchen et al., 2011). Further, individuals suffering from anxiety disorders often experience an additional anxiety or mood disorder. In the general population, comorbidity ranges from a prevalence of $81 \%$ for individuals with a primary diagnosis of agoraphobia to $28.6 \%$ for individuals with a primary diagnosis of specific phobia (Alonso et al., 2004b). In the clinical population, the lifetime prevalence for comorbidity is $81 \%$ (Brown, Campbell, Lehman, Grisham, \& Mancill, 2001).

Psychiatric conditions are often associated with reduced quality of life (Mendlowicz \& Stein, 2000; Olatunji, Cisler, \& Tolin, 2007), an increased risk of developing somatic disorders (Denollet, Maas, Knottnerus, Keyzer, \& Pop, 2009), and high societal costs (Smit et al., 2006). The World Health Organization (World Health Organization, 2001) expects that by the year 2020 anxiety disorders together with depressive disorders will represent the second greatest illness burden globally. The majority of people with these disorders are treated in primary-care settings (Stein et al., 2004; Swedish National Board of Health and Welfare [Socialstyrelsen], 2010; Wang et al., 2007), an arena in which the guideline treatments are not normally investigated. There is room for both improving patient satisfaction and quality of care for these patients (Stein et al., 2004; Wang et al., 2007) and for investigating the possible costeffectiveness of treatments for these conditions.

This thesis explored the possibility of using the Internet to treat patients suffering from anxiety regardless of comorbidities, and the central questions were whether tailoring the cognitive behavioural 
treatments delivered via the Internet is a feasible approach and whether the effects are sustained at longer term follow-ups. The aim was to test not only this treatment's effects but also, and above all, its effectiveness in primary-care.

\section{Anxiety disorders}

\section{Fear and anxiety}

Fear is an innate emotion represented in both humans and other species and an adaptive response to provide protection from potential harm. In humans, when fear is excessive, long-lasting and out of proportion in relation to the confronted situation, it can lead to the development of clinical anxiety. In clinical anxiety, worry, physical arousal and avoidance are present. These descriptions of fear and anxiety respectively implicate different definitions.

Fear was defined by Davis (2006) as "a rapid response system that mediates short-term responses to specific threat cues (i.e., stimulus specific fear responses)" (p. 750), anxiety as "a sluggish response system that, once activated, continues to influence behaviour long after the initiating stimulus has been terminated." (p. 750). Bouton, Mineka, and Barlow (2001) offered the following definition of panic (which here can be considered equal to fear) and anxiety, linking fear and anxiety to psychopathology:

"Panic is an immediate response to an insult to the organism; although it may involve cognitions about impending doom, it must have temporal and other properties that help the organism deal with a terrifying event that is already in progress. Anxiety, in contrast, is functionally organized to help the organism prepare for a possible upcoming insult. It is more 'forward looking' in this sense [...]." (p. 11)

Both studies implicate differences, at least on a behavioural level, between fear (or panic) and anxiety. But how are they learned?

Fear, or panic responses - seen as a rapid, immediate responsesare often learned through conditioning. Fear conditioning, a form of 
classical or Pavlovian conditioning, is established when a neutral stimulus (NS) is associated with an unconditioned stimulus (UCS), leading to an unconditioned reflex (UCR) a sufficient number of times. During Pavlovian conditioning, the NS becomes a conditioned stimulus (CS) that elicits a conditioned response (CR). The conditioned reflex is the CS-CR pairing. The CR does not have to be identical to the UCR, but it resembles it, and CR is often less intense and slower to appear. Noteworthy is that the stimuli most predictive of the onset of a reflex are usually the stimuli that become the CSs. When the animal or human learns that a CS predicts an aversive biological relevant event, such as pain, this is seen as a learned fear reaction (LeDoux, Schiller, \& Cain, 2009). Fear learning is often generalized to other stimuli that resemble the CS. In humans this is influenced by perceptual and emotional intensity dimensions of the stimuli (Dunsmoor, Prince, Murty, Kragel, \& LaBar, 2011). The possibility for generalization is efficient in that it allows the organism to treat novel stimuli properly, but it can also have maladaptive consequences, leading to an overgeneralization of fear to harmless stimuli. This is often a symptom of anxiety disorders in clinical practice. A learned CS can become a conditioned reinforcer that mediates the learning of other behaviours and becomes a conditioned motivation in the sense that it affects the motivation to perform previously learned behaviours (LeDoux et al., 2009). This makes fear conditioning more or less context dependent. In cued conditioning the CS is always predictive of the reflex, whereas in context conditioning it is not. Explicit threat cues are presumed to elicit fear responses, while contextual cues are presumed to elicit more sustained anxious responses (Craske et al., 2009). The explicit cues are cues of a certain threat, while the contextual cues are less specific and more like a reminder of a possible threat. Bouton et al. (2001) concluded that conditioning in humans engages whole systems of behaviour that are functionally organized according to each different UCS, and a different CS can therefore support constellations of behaviours that are not necessarily the same as the UCR.

Different forms of anxiety disorder

The subheading of anxiety disorders incorporates several diagnoses. The Diagnostic and Statistical Manual of Mental Disorders, fourth 
edition (DSM-IV; American Psychiatric Association, 2000) includes the following diagnoses: Panic disorder with or without agoraphobia, agoraphobia without history of panic disorder, specific phobia, social phobia, obsessive-compulsive disorder, posttraumatic stress disorder, acute stress disorder, generalized anxiety disorder, anxiety disorder due to a general medical condition, substanceinduced anxiety disorder, and anxiety disorder not otherwise specified. Recently the DSM has undergone a revision, and in the new edition (DSM-5; American Psychiatric Association, 2013a) obsessive-compulsive disorder, posttraumatic stress disorder, and acute stress disorders have been removed from the chapter on anxiety disorders. Obsessive-compulsive disorder heads a new chapter called "Obsessive-Compulsive and Related Disorders," and the other two are included under "Trauma- and Stressor-Related Disorders" (American Psychiatric Association, 2013b). The American Psychiatric Association still emphasizes the close relation to anxiety disorders through the sequential order of the chapters. Anxiety disorders now include separation anxiety disorder (new), selective mutism (new), specific phobia, social anxiety disorder, panic disorder, agoraphobia, generalized anxiety disorder, anxiety disorder due to another medical condition, other specified anxiety disorder, and unspecified anxiety disorder (American Psychiatric Association, 2013b).

This thesis covers only the following diagnoses: panic disorder with or without agoraphobia, agoraphobia without history of panic disorder, social phobia, generalized anxiety disorder, and anxiety disorder not otherwise specified. This choice reflects the fact that these are the disorders presented by the patients included in the studies as their primary diagnoses. Focus is placed on an adult population, and the fourth edition of DSM is used. However, any changes that appear in the fifth edition are briefly presented.

\section{Agoraphobia without history of panic disorder}

Agoraphobia is anxiety about being in situations or places that are difficult or embarrassing to escape from or in which help may not be available in case of a panic attack or panic-like symptoms (American Psychiatric Association, 2000). The feared situations are avoided or endured with distress, and persons with agoraphobia 
might engage in these situations only if a trusted companion is present. In DSM-5 (American Psychiatric Association, 2013a) the diagnosis is named simply agoraphobia and it must have a duration of at least six months to be a diagnosable condition.

People diagnosed with agoraphobia without a history of panic disorders often present panic-like symptoms but have never met the criteria for panic disorder (American Psychiatric Association, 2000). The twelve-month prevalence varies between $0.8 \%$ (Kessler et al., 2005) to $2 \%$ (Wittchen et al., 2011) in the general population.

As for all DSM-IV disorders, the symptoms should not be the result of any general medical condition (in DSM-5 this is stated as "another medical condition"), be the physiological effects of substance use, or be better explained by any other mental disorder.

\section{Panic disorder with or without agoraphobia}

Panic attacks are physical or somatic expressions of panic, such as sweating, dizziness, and nausea (Barlow, 2002). DSM-IV lists thirteen symptoms; both physical and cognitive (e.g., fear of losing control and fear of dying). For an episode to be defined as an attack, the person must experience four or more of the symptoms, and the attack must be characterized by intense fear or discomfort, develop abruptly, and culminate within ten minutes (American Psychiatric Association, 2000).

The essential feature of panic disorder is the presence of frequent (at least two) unexpected panic attacks followed by a minimum of one month of worry about having another attack, about the implications of the attack, or about its consequences, as well as considerably changed behaviour related to the attacks (American Psychiatric Association, 2000). An unexpected attack is by definition not immediately associated with a situational trigger (e.g., internal cues, or exposure to a phobic stimulus). The frequency and severity of attacks varies between individuals, and often panic attacks are misinterpreted as severe somatic disorders-for example, heart attacks. About one-third to half the patients diagnosed with panic disorder also meets the criteria for agoraphobia (American Psychiatric Association, 2000). In DSM-5 panic disorder with or 
without agoraphobia is divided into two diagnoses - panic disorder and agoraphobia (American Psychiatric Association, 2013a). Instead of one diagnosis for panic disorders with agoraphobia, two separate diagnoses are required.

The twelve-month prevalence in Sweden's general population is 2.2\% (Carlbring, Gustafsson, Ekselius, \& Andersson, 2002). These figures align with findings in other European countries (Wittchen et al., 2011).

\section{Social phobia}

Social phobia, or social anxiety disorder as it is named in DSM-5, is characterized by fear reactions triggered by a variety of social situations in which the person might be negatively evaluated by others. The social situations almost always trigger anxiety and are avoided or undergone only with great distress. The disorder is truly connected to social situations in that individuals report no difficulty when, for example, eating, writing, or speaking on their own - the deterioration in behaviour is connected only to other people's watching. Adults suffering from the disorder often realize that the fear is unreasonable (a criterion in DSM-IV but removed from DSM-5), and DSM-IV underlines that the fear and avoidance must interfere significantly with the person's daily functioning (i.e., daily routines, occupational functioning or studies, and social life) in order to indicate a possible diagnosis (American Psychiatric Association, 2000). Often anticipatory anxiety is present, and this may occur far in advance, leaving the person to worry extensively about upcoming social situations.

For a DSM-IV diagnosis, social phobia should be specified if generalized - that is, if it occurs in most social situations, both public performance and social interactional situations. In the fifth edition the specification has been changed to "performance only" (American Psychiatric Association, 2013a). Point prevalence for social phobia in the Swedish general population is $15.6 \%$ (Furmark et al., 1999), and the twelve-month prevalence in Europe is estimated to be $2.3 \%$ (Wittchen et al., 2011). 


\section{Generalized anxiety disorder}

The key feature of generalized anxiety disorder (GAD) is excessive anxiety and worry. The anxiety and worry must occur more days than not for a period of at least six months and must cover a number of themes and activities (American Psychiatric Association, 2000). The themes might shift from time to time, and the worry is experienced as difficult or impossible to control. Anxiety and worry are accompanied by a number of additional symptoms, including restlessness, difficulties sleeping, irritability, muscle tension, and so on. The intensity, duration, and frequency of worry are not proportional to the actual likelihood of the feared event, and even if individuals with GAD do not always find the worries excessive, they report distress or experience impairment in important areas of functioning (e.g., social, occupational, academic). The point prevalence in Sweden is $8.8 \%$ (Johansson, Carlbring, Heedman, Paxling, \& Andersson, 2013).

\section{Anxiety disorder not otherwise specified}

This category comprises anxiety disorders-including prominent anxiety and phobic avoidance - that do not meet the criteria for any specific anxiety disorder (American Psychiatric Association, 2000). A typical example is when the patient does not report enough symptoms to meet the criteria for any specific anxiety disorder. The diagnosis can also be relevant in situations where the clinician has concluded that an anxiety disorder is present but cannot determine whether it is primary, attributable to a general medical condition, or substance induced. Anxiety disorder not otherwise specified is used when the individual reports clinically significant distress and interference with daily functioning.

\section{Natural course}

An anxiety disorder often has its onset during adolescence. This varies however and while social phobia usually has its onset in the mid-teens, panic disorder starts either in adolescence or in the patient's mid-thirties. Spontaneous recovery from anxiety disorders exists, but the data are mixed. There is a relatively high probability of recurrence even if recovery has occurred at some time (Bruce et al., 2005). At twelve-year follow-ups, recovery rates were reported to vary between a 0.82 probability for panic disorder and a 0.37 
probability for patients with social phobia (Bruce et al., 2005). Even if a patient had recovered at some point during the twelve years, the rates for probability of recurrence still ranged from 0.58 to 0.39 (panic disorder without agoraphobia and social phobia, respectively). Rhebergen et al. (2011) presented that approximately $50 \%$ of those with an anxiety disorder no longer fulfilled the diagnosis criteria after seven years. Hendriks, Spijker, Licht, Beekman, and Penninx (2012) showed similar results regarding the two-year course, and Fichter, Quadflieg, Fischer, and Kohlboeck (2010) determined that around $60 \%$ no longer fulfilled their anxiety disorder diagnosis if no other co-occurring disorder was present after 25 years. A comorbid disorder might change these figures, however. Rehbergen et al. (2011) found that a comorbid state resulted in a poorer outcome at a seven-year follow-up in the group with mixed anxiety and mood disorder. Fichter et al. (2010) found that just over $50 \%$ fell into the category of "any mental disorder" at a 25 year follow-up, indicating that untreated anxiety disorders leave patients at risk for developing other mental disorders as well.

\section{Comorbidity}

Among individuals suffering from anxiety disorder, nearly half have at least one comorbid psychiatric condition (Alonso et al., 2004b). Owing to high figures of comorbidity among anxiety (and mood) disorders, researchers show growing interest in different explanations for this. There is evidence for shared phenotype in anxiety disorders and major depressive disorder, leading researchers to conclude that there is a single higher order internalizing (as opposed to externalizing) factor that accounts for correlations between anxiety disorders and mood disorders (Hettema, 2008).

Studies investigating recovery and recurrence of anxiety disorders found somewhat different paths for different anxiety disorders, but chances decreased for recovery when the patients suffered from more than one disorder. Considering possible predictors of these poorer outcomes showed several possibilities of clinical interest: avoidance behaviour (Hendriks et al., 2012), poor physical functioning, childhood adversity and high neuroticism (Rhebergen et al., 2011), and agoraphobic avoidance (Bruce et al., 2005). Moreover, the relationship between the number of comorbidities and the bur- 
den of disability possibly reflects the fact that the number of comorbidities is simply an indicator for severity or that avoidance behaviour increases with an increased number of disorders (Sherbourne et al., 2010).

One theory developed with this interest of "shared features" is David Barlow's triple vulnerability theory (Barlow, 1991; Barlow, 2002), which emphasizes a common etiological process with the focus on vulnerabilities connected to biological and psychological factors, generalized as well as specific. The general vulnerabilities Barlow (2002) described as biological as well as psychological, while the specific ones are connected only to psychological aspects. The specific psychological vulnerabilities are related to early learning and influence the development of one particular symptom versus another (e.g., panic attacks vs. fear of negative evaluation). Craske et al. (2009) aimed to investigate what an anxiety disorder might be, looking at features of responding. They concluded that anxiety disorders are characterized by an elevated sensitivity to threat (Craske et al., 2009) and an increased sensitivity in physiological, behavioural and cognitive responding. However, they reported difficulties distinguishing among anxiety disorders and separating depression from anxiety disorders, possibly owing to the high comorbidity rates.

\section{A cognitive behavioural model of anxiety}

The cognitive behavioural model for clinical anxiety implies that anxiety stems from dysfunctional cognitions and from classical and operant conditioning. The dysfunctional cognitions can be divided into two main categories: overstated evaluations of the likelihood of harm, and overstated evaluations of the severity of harm (Abramowitz, 2013). These two perceptions underlie responses to the triggers that characterize the different anxiety disorders, and over time the fear may become a conditioned response to such stimuli, which serve as triggers.

Classical and operant conditioning form the two core parts of learning theory. Classical conditioning (described earlier in association with fear conditioning) occurs when an NS is paired with an existing reflex, causing the NS to be associated with a UCS, producing 
conditioned responses to the previously neutral stimuli (Baldwin \& Baldwin, 2001). The reflex is a stimulus-response pattern in which a stimulus activates a biologically based response. The fear learning, or acquisition, can be in part clinical anxiety and fear, since the stimuli that become associated with fear might have very little to do with actual life-threatening events - for example, social events in social phobia.

Operant conditioning is learning through consequences of behaviour (Baldwin \& Baldwin, 2001). The central parts of operant conditioning are antecedent cues or discriminative stimuli, behaviour, and consequences. Antecedents set the circumstances for behaviour, while the behaviour causes the consequence (Baldwin \& Baldwin, 2001). Consequences are divided into reinforcing and punishing stimuli: a consequence is a reinforcer if it strengthens the behaviour, making it more frequent, and is a punisher if it causes the behaviour to become less frequent. When clinical anxiety is present, often a combination of classical and operant learning is involved (Mowrer, 1951;1956) The patient's history may contain situations in which the individual has learned to escape learned anxiety or fear-for example, a patient who acquires panic disorder with agoraphobia and avoids going to the grocery store because the store might evoke fear (Bouton, 2007).

Individuals who have acquired anxiety disorders often engage in socalled safety behaviours (Salkovskis, 1991), defined by their functions of helping the anxious person rapidly reduce fears and creating a sense of security in order to prevent a feared catastrophe. The rapid reduction of fear negatively reinforces the safety behaviours, and in the long term safety behaviour stops the natural extinction of classically conditioned fear. In short, safety behaviours are thought to uphold anxiety by promoting premature escape from anxiety and preventing disconfirmation of dysfunctional beliefs (Abramowitz, 2013).

Ultimately, the acquisition of fear and anxiety occurs via direct exposure to danger signals and dangerous stimuli through classical conditioning, direct negative reinforcement of escape from and avoidance of these stimuli and signals, observational learning (ob- 
serving others' reactions), and information regarding potentially dangerous stimuli (Lohr, Lilienfeld, \& Rosen, 2012).

\section{Psychological treatments of anxiety disorders}

Several psychological treatments have evolved to relieve individuals from anxiety disorders; some of these have proved to be effective. In 2005 the Swedish Council on Health Technology Assessment performed a systematic literature review on treatments for anxiety disorders (Swedish Council on Health Technology Assessment [SBU], 2005). The council stated that cognitive and behavioural treatments, or cognitive behavioural therapy (CBT), are the most studied and yield the greatest effects, and therefore they should be the treatment of choice. SBU did not recommend psychodynamic psychotherapy for any of the anxiety disorders because of its judgement that evidence of the treatment's efficacy was insufficient. Of course, critiques have emerged of the selection and evaluation of the studies included in the review (Sandell \& Böhm, 2006). Against CBT in general, a substantial criticism has been levelled regarding the use of randomized controlled trials (RCTs) in evaluating psychological treatments (Bohart \& House, 2009). Attempts to reanalyse data from RCTs and meta-analyses aiming to test the superiority of CBT to non-CBT treatments have shown that the superiority could not be replicated (e.g., Baardseth et al., 2013; Wampold et al., 1997). Regardless of the critique, in the 2010 guidelines for treatments of anxiety and mood disorders, very little was changed (Swedish National Board of Health and Welfare [Socialstyrelsen], 2010). CBT-and for some of the disorders, pharmacological treatment-was regarded as the treatment of choice for anxiety disorders. Without claiming that other forms of psychological treatments do not exist or are unhelpful in the treatment of anxiety, this thesis focuses on cognitive and behavioural treatments - in particular, on Internet-delivered CBT.

In the 2010 guidelines the board also presented the shortcomings of the competence of employees in treatment settings where the guidelines are executed, pointing out that costs would initially increase 
for these providers in bridging the gap between praxis and the recommendations. Nothing appeared in the guidelines about comorbidities. But comorbid depression does not seem to reduce effects of evidence-based protocols for anxiety disorders (Campbell-Sills et al., 2012). So while evidence-based treatments for anxiety disorders exist, only a small proportion of individuals who suffer from these disorders receive adequate treatment (Wang et al., 2007; Weisberg, Dyck, Culpepper, \& Keller, 2007; Wittchen \& Jacobi, 2005). Quite a large proportion of the patients who reported a need to seek treatment for their conditions did not do so because of attitudinal or evaluative barriers (e.g., the presence of stigma, low perceived efficacy of treatments, or the desire to handle the problem on their own; Mojtabai et al., 2011). On the other hand, Prins, Verhaak, Bensing, and van der Meer (2008) found that patients with anxiety disorder (with comorbidities presented in almost half of the samples) perceived psychological treatments as more positive and effective than medication, even though medication can be effective (Baldwin et al., 2005). It has been reported that general practice patients with anxiety or depression expressed a need for counselling or information to a greater extent than they did for medication, and that the patients preferred psychological interventions (Prins, Verhaak, van der Meer, Penninx, \& Bensing, 2009). This also seems to be true of patients with a primary diagnosis of depression (Van Schaik et al., 2004).

\section{Cognitive behavioural therapy}

CBT is an encompassing term comprising both cognitive and behavioural treatments and has been investigated for a long time. Given its wide scope, it includes diverse methods and techniques ranging from exposure therapy to applied relaxation, mindfulness, and cognitive restructuring.

The first RCT on a behavioural treatment was Lang and Lazovik (1963), who examined the effects of repeated exposure to a phobic object (i.e., snake). Even though today's treatments may not yield more beneficial effects than these initial studies did (Öst, 2008), CBT has in numerous studies proved effective both post-treatment and in follow-ups (Butler, Chapman, Forman, \& Beck, 2006; Hofmann, Asnaani, Vonk, Sawyer, \& Fang, 2012), rendering it the 
first-order treatment for anxiety disorders. Stewart and Chambless (2009) found superiority of CBT over control conditions with large effect sizes and $78 \%$ improvement rate (vs. $22 \%$ for control conditions) in effectiveness trials on adult anxiety patients. Indicating that most but far from all patients with anxiety, benefit from CBTtreatments.

CBT for anxiety disorders typically includes psychoeducation, sometimes applied relaxation, cognitive restructuring, and behavioural experiments, but a large component of CBT for anxiety disorders is exposure therapy. Exposure therapy comprises a set of techniques that involves helping the patient engage in repeated and sometimes prolonged confrontation with a feared stimulus (Abramowitz, 2013). The aim of this confrontation is to reduce the conditioned fear response associated with this stimulus (extinction), and over time this response declines (habituation). Habituation is not thought necessary for extinction learning to occur during exposure (Craske et al., 2008). Instead, exposure is seen as inhibitory learning - the fear associations are not removed but rather remain intact during extinction, and new learning about the feared stimulus simultaneously occurs - leaving at least two available responses to the feared stimulus after successful exposure therapy (Bouton, 2002). This shapes the way in which the patient expresses fear, possibly improving the patient's tolerance of fear and increasing the possibility that the second response learned, the inhibitory association, will be displayed (Arch \& Craske, 2011).

Psychoeducation is the introductory first part of CBT and consists of (sometimes corrective) information about the presented problems of anxiety or panic. A CBT explanation is offered for how the problems develop and are sustained in terms of learning and reinforcements, and emphasis is placed on normalizing the experience of anxiety or panic. Psychoeducation also includes a rationale for the treatment components and why to use them. This is important when exposure is included because exposure is normally seen as punitive in that the person is exposed to feared situations and emotions. Therefore, it is extremely important to render exposure a rewarding event. 
In applied relaxation (Öst, 1987) individuals is taught progressive muscle relaxation and learn to become relaxed more and more quickly over the course of treatment. Finally, patients are taught to relax in the presence threat cues and in real-world situations.

Cognitive restructuring or modification includes identifying, registering, and rationally questioning negative automatic thoughts (NATs; Beck, 1979). NATs are negative in the way they influence behaviour and automatic in the way that they seem to come quickly to mind without effort. The goal in restructuring is to modify the individual's misinterpretations. Behavioural experiments are designed to test the validity of NATs in the "real world."

As of this writing, at least one cognitive and one behavioural treatment has proved to be evidence based for anxiety disorders in adults (Öst, 2008). The Swedish 2010 guidelines (Swedish National Board of Health and Welfare [Socialstyrelsen]) presented CBT as the treatment of choice, along with pharmacological therapy for some anxiety disorders. This implies that the National Board of Health and Welfare values CBT as evidence-based treatment for these disorders. The board's guidelines, however, do not address comorbidity.

\section{Internet-based cognitive behavioural therapy}

In an attempt to lower the barriers to seeking and receiving treatment, Internet-based cognitive behavioural therapy (ICBT) has been developed. ICBT has been shown to be as effective as conventional CBT for depression and anxiety when compared both at posttreatment and at follow-up (Andersson, Cuijpers, Carlbring, Riper, $\&$ Hedman, in press). ICBT, in the form used by our research group, can be defined as:

"a therapy that is based on self-help books, guided by an identified therapist, which gives feedback and answers to questions, with a scheduling that mirrors face-to-face treatment, and which can also include interactive online features such as queries to obtain passwords in order to get access to treatment modules." (Andersson et al., 2008 p. 164)

This approach is different from pure self-help, in which no feedback is given from the clinician, and is therefore sometimes referred to as guided self-help — as opposed to unguided or pure self-help. Includ- 
ing guidance is important in order to optimize outcomes (Almlöv, Carlbring, Berger, Cuijpers, \& Andersson, 2009; Palmqvist, Carlbring, \& Andersson, 2007; Spek et al., 2007), albeit there is some evidence that support from a technical point of view (i.e., support from a coach or technician not aiming to be therapeutic) can acquire results comparable to those of a clinician or therapist (Johnston, Titov, Andrews, Spence, \& Dear, 2011; Robinson et al., 2010; Titov, Andrews, Davies, et al., 2010; Titov et al., 2009).

ICBT has proved effective for a variety of anxiety and mood disorders (Hedman et al., 2012; Andrews, Cuijpers, Craske, McEvoy, \& Titov, 2010; Cuijpers et al., 2009; Reger \& Gahm, 2009; Spek et al., 2007). The evidence base for the clinical feasibility of ICBT is growing, showing promising results, with medium to large withingroup and small to medium between-group effect sizes (Bell, Colhoun, Carter, \& Frampton, 2012; Hedman et al., 2013; Hoifodt, Strom, Kolstrup, Eisemann, \& Waterloo, 2011; Mewton, Wong, \& Andrews, 2012; Roy-Byrne et al., 2010; Ruwaard, Lange, Schrieken, Dolan, \& Emmelkamp, 2012). Nevertheless, there seem to be differences between diagnoses. Seekles, van Straten, Beekman, van Marwijk, and Cuijpers (2011) showed that ICBT decreased symptoms of anxiety disorders but not those of depression, compared to treatment as usual in a primary-care sample. Newby et al. (2013) showed ICBT to be effective for mixed anxiety and depression in a primary-care setting, but struggling with low adherence, they concluded that efforts should be placed on improving adherence when implementing routine care.

Questions arise concerning the security of electronic information and technical difficulties (Yuen, Goetter, Herbert, \& Forman, 2012), and data security is important when delivering treatment through the Internet. The systems we work with are encrypted and have a double authentication procedure at log-in, a system similar to the one used by options to pay bills via the Internet.

\section{Adherence and drop-out}

High drop-out rates and high attrition are sometimes perceived as making a study less generalizable. In eHealth there have been suggestions that attrition data is important because it gives clues about real-life adoption problems of new innovations (Eysenbach, 2005); 
therefore, it is important to publish studies with high proportions of drop-out as well. A distinction should be made between drop-out and low- or non-usage. Low usage and drop-out are not necessarily failures; drop-out might represent different paths and could mirror fulfilled needs after fewer modules than expected (Christensen \& Mackinnon, 2006). To handle high drop-out rates it has been suggested that researchers make use of intention-to-treat analyses instead of completers' analysis and that they report attrition proportions at different time points (Christensen \& Mackinnon, 2006; Eysenbach, 2005).

Data suggests that there are no differences in drop-out rates between guided self-help and conventional CBT (Cuijpers et al., 2010; Lewis, Pearce, \& Bisson, 2012). However, the drop-out rates varies substantially. In a recent review concerning attrition and drop-out in conventional cognitive and behavioural treatments, as well as medication for individuals with anxiety disorders, drop-out rates ranged from $10 \%$ to $85 \%$ (median $=28 \%$; mean $=36 \%$; Santana \& Fontenelle, 2011). A meta-analysis of effectiveness studies by van Ingen, Freiheit and Vye (2009) showed a mean drop-out rate for adult patients with anxiety disorders to be $26.8 \%$, while Hans and Hiller (2013) presented a mean drop-out rate of $15.06 \%$ in their meta-analysis of non-randomized effectiveness studies on outpatient CBT for anxiety disorders. In the Hoifodt et al. (2011) review of ICBT, drop-out rates fluctuated between $0 \%$ and $88 \%$, and the majority of the studies reported drop-out ranging from $15 \%$ to $30 \%$. Measuring adherence (defined as the proportion of patients starting the first session who also completed the final session), the results vary. Newby et al. (2013) found that $41 \%$ completed the programme for mixed anxiety and depression, Mewton et al. (2012) reported 55\% adherence for GAD patients, and Ruwaard et al. (2012) showed 76\% adherence for PTSD patients. All these figures are from effectiveness trials. Generally, adherence is higher in selfrecruited samples than in clinical samples, and it may be lower in heterogeneous samples.

Single protocols

One common critique of CBT, as well as of ICBT, is the use of a single strict protocol targeting a specific disorder - resulting in the 
development of multiple protocols for each DSM-IV disorder, many of them without empirical support justifying the changes (Wilamowska et al., 2010). This leaves the clinician with the sometimes difficult task of choosing among them. Another critique of single protocols is that many RCTs in this arena suffer from substantial exclusion rates because one specific primary diagnose is selected and large proportions of the patients present another primary diagnose, yet suffering from the studied anxiety disorder as well. For example, in Carlbring et al. (2006), only 60 participants were randomized from an initial sample of 358 individuals who applied for participation. Another critique is that single protocols require a diagnosis and leave no room for intuitive actions based on the exigencies of each individual's situation (Lees, 2009).

One way of trying to deal with this is to make use of a unified, still single, treatment protocol, such as the "Unified Protocol" (Barlow, Allen, \& Choate, 2004), which focuses not on the specific diagnosis but on the features shared among all emotional disorders. This type of treatment, administered through the Internet, has been shown to be a feasible approach for people with a primary anxiety disorder (Dear et al., 2011; Titov, Andrews, Johnston, Robinson, \& Spence, 2010; Titov et al., 2011); it has demonstrated medium to large effect sizes at post-treatment (see Table 1 for details). Online treatment administration is also effective when tailoring the treatment to patients' unique characteristics and preferences. 
Table 1. Outcome studies of transdiagnostic ICBT for patients with primary diagnoses of generalized anxiety disorder, panic disorder (with or without agoraphobia), and social phobia.

$\begin{array}{llll}\text { Study Design } & \begin{array}{l}\text { Primary } \\ \text { outcome } \\ \text { measure }\end{array} & \begin{array}{l}\text { N at } \\ \text { start }\end{array} & \begin{array}{l}\text { Follow- } \\ \text { up }\end{array}\end{array}$

\begin{tabular}{|c|c|c|c|c|c|}
\hline $\begin{array}{l}\text { Titov, } \\
\text { Andrews, } \\
\text { Johnston, et al. } \\
(2010)\end{array}$ & $\begin{array}{l}\text { RCT com- } \\
\text { paring to } \\
\text { control }\end{array}$ & GAD-7 & 86 & 3 months & $\begin{array}{l}\text { On GAD-7 a between-group effect size of } \\
d=.78 \text { was found post-treatment, and the } \\
\text { within-group effect was } d=.73 \text { at follow-up. } \\
\text { For secondary outcome measures, small to } \\
\text { moderate between-group effects were found } \\
\text { at post-treatment, and small to moderate } \\
\text { within-group effects were found from pre- } \\
\text { treatment to follow-up. }\end{array}$ \\
\hline
\end{tabular}

\begin{tabular}{|c|c|c|c|}
\hline $\begin{array}{l}\text { Dear et al. } \\
(2011)^{*}\end{array}$ & $\begin{array}{l}\text { Single- } \\
\text { group open } \\
\text { trial }\end{array}$ & $\begin{array}{l}\text { GAD-7 } \\
\text { DASS-21 }\end{array}$ & 32 \\
\hline
\end{tabular}

\begin{tabular}{|c|c|c|c|}
\hline $\begin{array}{l}\text { Titov et al. } \\
\text { (2011)* }\end{array}$ & $\begin{array}{l}\text { RCT com- } \\
\text { paring to } \\
\text { control }\end{array}$ & $\begin{array}{l}\text { GAD-7 } \\
\text { DASS-21 }\end{array}$ & 77 \\
\hline
\end{tabular}

$\begin{array}{lllll}\text { Johnston et al. } & \begin{array}{l}\text { RCT com- } \\ \text { (2011) }\end{array} & \text { GAD-7 } & 139 & 3 \text { months } \\ \text { paring to } & \text { DASS-21 } & & \\ \text { control and } \\ \text { coach- } \\ \text { supported } \\ \text { ICBT }\end{array}$
Within-group effects were $d=1.06$ for GAD-7 and $d=1.10$ for DASS-21 at post- treatment. At follow-up the effects were $d=.95$ for GAD-7.and $d=1.05$ for DASS- 21. For secondary outcome measures, the within-group effects were large to moderate at both post-treatment and follow-up meas- urements.

On primary outcome measures, the between-group effect sizes were moderate (GAD-7, $d=.52$; DASS-21, $d=.56$ ), and large within-group effects for GAD-7 $(d=.94)$ and DASS-21 $(d=1.00)$ were shown at follow-up. For secondary outcome measures, small between-group effect sizes were shown at post-treatment and small to moderate within-group effects at follow-up.

Effect sizes were calculated combining the two treatment groups (coach- and cliniciansupported), and the effects at post-treatment were $d=1.44$ on GAD- 7 and $d=.94$ on DASS-21. At follow-up the within-group effects were $d=1.03$ for GAD-7 and $\mathrm{d}=1.00$ for DASS-21. For secondary outcome measures, results show moderate to large between-group effect sizes at posttreatment and moderate to large withingroup effect sizes at follow-up.

* In addition to anxiety diagnoses, depression was included.

Abbreviations: RCT, randomized controlled trial; GAD-7, Generalized Anxiety Disorder 7-item scale; DASS-21, Depression Anxiety Stress Scale-21 item. 
Why tailor the treatment?

The process of making the perfect match in psychological treatments has one goal: to improve treatment outcomes by considering each patient's unique situation. While transdiagnostic unified approaches are concerned about the underlying processes in anxiety, often using a single protocol, tailored treatment seems to address these processes and the patients' preferences and presented problems. The patient in a tailored treatment can play an active part in deciding the amount of text, the time necessary to finish one chapter, and the order in which to address the presented problems. The choice of course has proved to enhance adherence to and possibly the effectiveness of ICBT (Hilvert-Bruce, Rossouw, Wong, Sunderland, \& Andrews, 2012). When comparing tailored ICBT with diagnosis specific ICBT for symptoms of SAD, GAD and PD in a self-recruited sample both treatments were found to be equally effective (Berger, Boettcher \& Caspar, in press).

Tailored programmes can be seen as empirically driven rather than theory driven; in the former type, all the used chapters or modules have been used with success in strict, single-disorder protocols. A transdiagnostic (i.e., single) protocol, on the other hand, regardless of which existing manual one investigates, is a theory-driven approach the evidence base of which is still being constructed. However, the same theories trying to explain psychopathology (e.g., Barlow, 2002) may be used to argument for both tailored and single unified treatment protocols, given that emphasis is placed on different aspects of the theory.

Further, the use of a tailored protocol may better align with the objective in many primary-care facilities, to deliver health care for the well-being of the individual, and to thus minimize the possible preconception that CBT treatment in general is appropriate only for large samples and that it ignores the individual and his or her preferences. In addition, therapists using a tailored protocol can make use of skills from conventional face-to-face treatment and possibly lower the barriers for practitioners to use ICBT.

It is still unclear whether diagnoses should be addressed separately, whether all anxiety disorders (and mood disorders, if presented) 
benefit from a single treatment protocol in the form of unified protocols (Craske, 2012), or whether treatment should be administered according to disorder-specific protocols (Olatunji, Cisler, \& Tolin, 2010). There is some evidence that comorbidities do not threaten the clinical effect when using diagnosis-specific treatment protocols (Bauer, Wilansky-Traynor, \& Rector, 2012; Olatunji et al., 2010). One possibility is that a personalized, or tailored, transdiagnostic approaches might be applicable and might even enhance treatment effects.

\section{Working alliance}

The working, or therapeutic, alliance is one of the concepts regarded as common to all forms of psychotherapy. Bordin (1979) proposed a model consisting of three parts - task, bond, and goalwhich he stated could apply to all "change situations" (p. 252 in Bordin, 1979). He suggested that the working alliance was a key factor in these change situations, in which a person tries to achieve change with the assistance of another person, and argued that the concept was universally applicable to all forms of psychotherapy. To state that the working alliance is a common factor may be misleading, however, since the way in which an alliance benefits specific treatments may not be common-it might, in fact, be specific (Hoffart, Borge, Sexton, Clark, \& Wampold, 2012), even if its importance is common. There have also been suggestions that working alliance functions differently in different therapies (Ulvenes et al., 2012), and should possibly be measured in this respect. For example, Andrusyna, Tang, DeRubeis, and Luborsky (2001) proposed that alliance in CBT should be measured using a two-factor model consisting of agreement/confidence and relationship rather than using Bordin's original three-part model.

Since the publication of Bordin's original paper, the working alliance has been investigated in numerous studies. The results of this research on the relationship between working alliance and outcome indicate that there is a correlation between a client-rated working alliance and the post-treatment outcome in a variety of disorders and psychological treatments (Flückiger, Del Re, Wampold, 
Symonds, \& Horvath, 2012; Horvath \& Symonds, 1991). Evidence suggests the superiority of client-rated working alliance measured at the beginning of treatment (usually session 3 or 4) in predicting outcome (Horvath \& Symonds, 1991). However, the results are mixed (Flückiger et al., 2012; Horvath, Del Re, Fluckiger, \& Symonds, 2011). These correlation effects seem fairly robust and independent of both study design (Flückiger et al., 2012) and type of treatment (Horvath et al., 2011), and they have been replicated in physical rehabilitation (Hall, Ferreira, Maher, Latimer, \& Ferreira, 2010). It seems possible that it is the therapist's ability to form an alliance — not the patient's input - that accounts for the correlation between working alliance and outcome (Baldwin, Wampold, \& Imel, 2007). In sum, a body of evidence indicates that a working alliance, especially if rated by the patient, is an important factor in predicting treatment outcome, even if the way this correlation works is largely unknown.

It is clear that a relationship can be formed via the Internet (Parks \& Roberts, 1998) and that the therapeutic relationship or working alliance appears to be similar as in face-to-face ratings (Cook \& Doyle, 2002; Preschl, Maercker, \& Wagner, 2011; Sucala et al., 2012). To what extent the quality of the working alliance correlates with the outcome is not clear. The data is somewhat mixed, showing no significant correlations between outcome and alliance when using a strict protocol (Andersson et al., 2012; Knaevelsrud \& Maercker, 2006). It is however possible that tailoring the ICBT treatment increases the importance of the working alliance (as Study II indicates).

\section{Cost-effectiveness}

A Swedish study reported that anxiety disorders accounted for $14 \%$ of the total cost connected to psychiatric conditions in 2004 (Sobocki, Allgulander, Hillert, \& Jönsson, 2004), and that total costs for all psychiatric conditions were estimated as 3\% of the Swedish gross domestic product (GDP), or SEK 10.000 per inhabitant (approximately USD 1.500). The largest proportion of these 
costs $(37 \%)$ was connected to indirect expenses - for example, production losses due to sickness pension and sick leave (Sobocki et al., 2004). In light of this, it is clear that in order to investigate interventions that would lower these figures, researchers must investigate the possible economic benefits of treatments.

Cost-effectiveness analysis (CEA) is a method of evaluating the cost and outcome of health-improving interventions (Russel et al., 1996). Implicitly, it relies on the notion that societal resources are limited and that health should not be excluded from those limits and could serve as an aid in making decisions about resource allocation. The central measure used in CEA is the cost-effectiveness ratio (ICER), which is a comparison of alternatives regarding treatment effectiveness and costs (Garber, Weinstein, Torrence, \& Kamlet, 1996). The costs include all medical and nonmedical costs of the participants, and effects can be measured either by symptom improvement (e.g., clinical significant improvement on primary outcome measures) or by quality-adjusted years (QALYs), which is a measure of the number of healthy years of life that are valued as equal to actual health outcome (Garber et al., 1996). The type of CEA that uses QALYs is sometimes labelled cost-utility analysis.

The cost-effectiveness of ICBT is largely unknown, but there is growing interest in the question. A recent review on effectiveness and cost-effectiveness of ICBT showed that the treatment was more cost-effective than no treatment and conventional CBT (Hedman, Ljótsson, \& Lindefors, 2012). It is noteworthy that only eight of the 108 studies included provided data regarding cost-effectiveness.

\section{Enduring effects}

Long-term effects of anxiety treatments for adult patients could be divided into at least two aspects: efficacy (effects gained in highly specific selected samples often in RCTs) and effectiveness (results obtained in more clinically representative samples and settings).

Hollon, Stewart, and Strunk (2006) suggested that efficacious treatments can be subdivided into three categories: some may be 
considered palliative - that is, they suppress symptoms as long as they are supplied; some may be considered curative, eradicating or reversing the underlying process that would contribute to the continuation of the disorder; and others may be considered prophylactic, interventions that prevent onset. This distinction is of interest when looking at treatment effects in long-term follow-ups. An enduring effect, in order to be worthy of the name, must be sustained after the intervention has been terminated. Hollon et al. (2006) argued that a treatment has enduring effects even if problems return, provided the problems are less intense than they would have been without treatment. This would be difficult to investigate. In most RCTs the control condition is treated after the post-treatment measurements - probably the most ethical procedure. Nevertheless, this method leaves some questions unanswered. Follow-ups after longer period of time may measure something other than actual treatment effects. The former participants continue living their lives, and knowing whether the treatment effects themselves are being measured is difficult. Individuals may feel either better or worse because of many factors, not only because of the specific treatment. This question is relevant at post-treatment, as well.

\section{Enduring effects of CBT and ICBT}

The follow-up studies investigating long-term effects of psychological treatments rarely extend beyond one-year post-treatment. Durham et al. (2005) investigated the effects of CBT for anxiety disorders in clinical trials after 2-14 years and found that over half the participants still fulfilled at least one set of diagnosis criteria at long-term follow-up. The majority of the patients in Durham et al. (2005) had received further treatment during this follow-up period, and $19 \%$ reported almost constant treatment. Even so, 38\% were reported to have achieved a sustained recovery, with no clinical diagnoses and little or no interim treatment during the follow-up period (Durham, Higgins, Chambers, Swan, \& Dow, 2012). Compared to prognosis without treatment for individuals suffering from anxiety, CBT may constitute a viable option (Bruce et al., 2005).

There is growing evidence for the long-term effects of ICBT (Carlbring, Nordgren, Furmark, \& Andersson, 2009; Hedman et al., 2011; Paxling et al., 2011), yet other research has found that alt- 
hough guided self-help yielded positive effects immediately after treatment, this effect is reduced at long-term follow-up points (Coull \& Morris, 2011).

\section{Anxiety disorders and their treatment in primary-care}

According to the Swedish National Board of Health and Welfare, most patients with anxiety disorders seek treatment in primary-care settings. SBU stated that as many as $70 \%$ of the patients with anxiety disorders are treated in primary-care (Swedish Council on Health Technology Assessment, 2005). More often than not, the gatekeeper for specialized treatment is a general practitioner (GP), making it vital that GPs receive information and education about the features of anxiety disorders and the evidence base for treatments of this patient group - particularly given that GPs play a role in introducing and motivating patients to follow through with treatment (Seekles et al., 2011). Only about half the patients with anxiety disorders who are treated in primary care reported receiving any mental-health treatment (psychological or pharmacological), and analyses showed that primary care physicians may have a high threshold for recognition and treatment of anxiety disorders, offering treatment only to patients with higher comorbidities and lower global functioning (Weisberg et al., 2007). Noteworthy is that primary-care patients suffering from anxiety do not always present their problems in psychological terms, and that is one possible reason for the failure of the GPs to recognize less severe mental-health problems (Seekles et al., 2011). Physicians should also be observant of substantial comorbidity in patients with anxiety disorders and of its effect on recovery and disability.

In a review of effectiveness for CBT delivered in primary-care by primary-care staff, it seems that CBT self-help and Internetdelivered CBT (or computerized CBT) were more effective than treatment-as-usual (Hoifodt et al., 2011). The same authors concluded that conventional CBT administered face-to-face was also effective, but only when administered by highly educated therapists. 
Possible ways to implement evidence-based treatments in primary care

In an effort to make evidence-based treatments for anxiety disorders accessible in clinical settings, the Coordinated Anxiety Learning and Management (CALM) project was launched (Craske et al., 2009), and it included computerized CBT. This is one of the largest randomized trials for the collaborative care of anxiety disorders, and the clinics ranged in type from private to members of health maintenance organizations and community health care centres (Curran et al., 2012).

In addition to examining the obvious clinical effectiveness aspect (see, Craske et al., 2011; Roy-Byrne et al., 2010), the researchers also investigated how clinicians and staff with no or limited experience of mental-health care experienced the training, the programme, and the treatment, concluding that CALM was acceptable to the clinicians, especially in structure (e.g., a clear agenda, overall structure, possibility of compiling and printing individualized workbooks) and as a user-friendly guide for CBT concepts.

Improvements were requested in areas of simplification (e.g., adjusting the language and reducing the amount of text) and increasing the programme's flexibility (Craske et al., 2009). Barriers to implementation, detected in Curran et al. (2012), were connected to provider attitudes (e.g., uneven physician support, feeling that prevalence of anxiety is low in their clinic), patient characteristics (e.g., low socioeconomic status and high overall disease burden), clinical structure (e.g., high prevalence of part-time providers), and intervention characteristics (e.g., communication with anxiety clinical specialists were unsatisfactory). On the other hand, the majority of the informants reported improvements in enough patients to value the intervention and stated a desire that it continue after the study's conclusion (Curran, et al., 2012).

United Kingdom has seen a far-reaching implementation of evidence-based practice in primary care through the Improving Access to Psychological Therapies (IAPT) programme for depression and anxiety disorders, starting in 2006. 
Following the guidelines from the National Institute for Clinical Excellence (NICE, 2005), CBT was to be offered to all patients with anxiety disorders and depression using a stepped-care model; mild to moderate depression and some anxiety disorders were to benefit from "low-intensity" treatments, self-help (guided or unguided) or computerized treatment programmes, later scaling up to "high-intensity," or conventional face-to-face, treatments.

Treatment offers consist of evidence-based protocols for specific disorders, and therapists are trained in these protocols exclusively. These therapists should be offered supervision with experts in order to acquire the necessary skills in achieving the preferred outcome (Barlow, Bullis, Comer, \& Ametaj, 2013). The first evaluation revealed positive results regarding treatment effects both posttreatment and at a ten-month follow-up, with approximately half the sample categorized as recovered (Clark et al., 2009). Results were replicated in a two-year prospective cohort study by Richards and Borglin (2011). It is interesting that the majority of patients were treated using the low-intensity interventions. 


\section{EMPIRICAL STUDIES}

Table 2 present the characteristics of the included participants in both RCTs.

Table 2. Demographic characteristics of participants at baseline and drop-out rates during treatment.

\begin{tabular}{|c|c|c|c|c|c|}
\hline & & & dy I & & ly III \\
\hline & & $\begin{array}{l}\text { Treatment } \\
(\mathrm{n}=27)\end{array}$ & $\begin{array}{l}\text { Control } \\
(\mathrm{n}=27)\end{array}$ & $\begin{array}{l}\text { Treatment } \\
(\mathrm{n}=50)\end{array}$ & $\begin{array}{l}\text { Control } \\
(\mathrm{n}=50)\end{array}$ \\
\hline Gender & Female & 18 & 23 & 33 & 30 \\
\hline & Male & 9 & 4 & 17 & 20 \\
\hline Age & Mean (SD) & $39.3(11.2)$ & $38.3(10.3)$ & $35(13)$ & $36(12)$ \\
\hline & Min-Max & $22-63$ & $25-62$ & $20-68$ & $19-60$ \\
\hline Marital status & Married/living together & 17 & 19 & 25 & 38 \\
\hline & In a relationship & & & 3 & 3 \\
\hline & Single & 9 & 3 & 20 & 9 \\
\hline & Other & 1 & 4 & 2 & 0 \\
\hline Highest educational & Nine-year compulsory school & 2 & 2 & 0 & 0 \\
\hline level & Secondary school & 7 & 5 & 13 & 10 \\
\hline & Vocational school (compl.) & 4 & 3 & 4 & 5 \\
\hline & College/university (not compl.) & 2 & 7 & 13 & 14 \\
\hline & College/university (compl.) & 12 & 10 & 20 & 21 \\
\hline Employment & Employed full or part time & 18 & 12 & 21 & 26 \\
\hline status & Registered sick & 2 & 2 & 4 & 8 \\
\hline & Unemployed & 2 & 3 & 6 & 1 \\
\hline & Student & 3 & 8 & 16 & 15 \\
\hline & Other & 2 & 2 & 3 & 0 \\
\hline Psychotherapy & None & $15(56 \%)$ & $16(59 \%)$ & $17(34 \%)$ & $19(38 \%)$ \\
\hline & Earlier & $12(42 \%)$ & $11(41 \%)$ & $33(66 \%)$ & $31(62 \%)$ \\
\hline Medication* & None & $11(41 \%)$ & $11(41 \%)$ & $21(42 \%)$ & $22(44 \%)$ \\
\hline & Earlier & $8(30 \%)$ & $10(37 \%)$ & $15(30 \%)$ & $16(32 \%)$ \\
\hline & Ongoing & $8(30 \%)$ & $6(22 \%)$ & $14(28 \%)$ & $12(24 \%)$ \\
\hline Drop-out & & 0 & $1(3.7 \%)$ & $3(6 \%)$ & $8(15 \%)$ \\
\hline
\end{tabular}

*Included both anxiolytic and antidepressant. 
Study I. Individually tailored, Internet-based treatment for anxiety disorders: A randomized controlled trial

\section{Aim}

The aim of this study was to investigate the effects of tailored Internet-based CBT for a self-recruited sample of patients with anxiety disorders and comorbidities. In order to detect sustained effects, one- and two-year follow-ups were included.

\section{Methods}

Participants were recruited from a waiting list consisting of people expressing interest in Internet-based treatments for social phobia, panic disorder, and generalized anxiety disorder. Time on the waiting list ranged from one day to two years. Those interested in participating were directed to a website created for the study. In addition to an outline of the study, the website included a presentation of the therapists and researchers involved in the study, and an application for participation. Applying required the participant to print out and send in an informed consent form and to complete computerized screening consisting of the Clinical Outcomes in Routine Evaluation-Outcome Measure (CORE-OM; Barkham et al., 2001), the self-rated version of the Montgomery Åsberg Depression Rating Scale (MADRS-S; Svanborg \& Åsberg, 1994), the Beck Anxiety Inventory (BAI; Beck, Epstein, Brown, \& Steer, 1988), the Quality of Life Inventory (QOLI; Frisch, Cornell, Villanueva, \& Retzlaff, 1992), and ten additional questions regarding demographics and current and past treatment. Applicants who fulfilled the initial inclusion criteria according to the screening were interviewed face-to-face using the Structured Clinical Interview for DSM-IV axis I disorders (SCID-I; First, Gibbon, Spitzer, \& Williams, 1997). To be included, participants had to meet the DSMIV-TR (American Psychiatric Association, 2000) criteria of any specific anxiety disorder or an anxiety disorder not otherwise specified. Further, the participants had to be at least 18 years old, score less than 31 total or less than 4 points on item 9 (suicidal thoughts) on the MADRS-S, and be receiving no current psychotherapy. If they were on medication, the dosage must have remained unchanged for at least twelve weeks, and participants were required to 
have access to a computer with Internet. Comorbidity did not serve as a criterion for exclusion. A total of 137 individuals were assessed for eligibility, and after the diagnostic interview 54 participants were included.

Participants were randomized to either treatment or control condition. For the control group a confidential, monitored online forum was used in which the patients were asked to post questions once a week on a predetermined topic presented by a therapist. The treatment consisted of a combination of disorder-specific modules for panic disorder (Carlbring et al., 2006), social phobia (Andersson et al., 2006), generalized anxiety disorder (Paxling et al., 2011), and depression (Vernmark et al., 2010), all of which have been tested in single protocol trials. The modules were slightly revised to better fit the tailored format, and all were based on established CBT methods. The module a participant was assigned and the order of modules were decided based on both SCID-I protocols and patient preferences. The first module (introduction) and the last (relapse prevention) were fixed. Each module included information and exercises and ended with essay-style questions. Participants were asked to answer these questions and to send the answers, along with worksheets and reports on outcome, to their therapists. Individual feedback was given within 24 hours. If the therapist judged the module as completed, the password to the next treatment module was sent to the patient. The mean total time spent on each participant was 15 minutes, including reading and responding to e-mail messages, as well as administration.

All measures were collected through the Internet, and participants were contacted via e-mail or surface post to fill in the same computerized screening post-treatment and for the one- and two-year follow-ups. Following the two-year measurement, participants were interviewed via telephone, and a clinical global impression of improvement (CGI-I; Guy, 1976) was administered by an assessor without knowledge of group allocation.

Analyses were conducted using two different approaches. From preto post-treatment the missing data stem only from the treatment group, and therefore the last observations carried forward were used to impute data. Results were then calculated using repeated measure 
ANOVAs. Results at follow-up were calculated using a linear mixed model with an autoregressive covariance structure. Effect sizes (Cohen's $d$ ) were calculated with observed means at posttreatment and by estimated means from the mixed model at followup divided by the pooled standard deviation (SD). SDs at follow-up were converted from standard errors $(\mathrm{SE})$ by the formula $\mathrm{SD}=$ $\mathrm{SE}^{*} \sqrt{\mathrm{N}}$.

\section{Results and brief discussion}

Results post-treatment showed significant interaction effects on anxiety, depression, and quality of life measures and small to large between-group effect sizes in favour of the treatment, with a mean effect size of $d=0.69$. From pre-treatment to the one-year followup, moderate to large within-group effect sizes were shown, and these effects were sustained at the two-year follow-up. However, the improvement in the quality of life measure was no longer significant. The CGI rating at post-treatment revealed that the majority of patients had greatly improved and none had deteriorated. After two years these figures showed that $41 \%$ were much improved and $2.4 \%$ were greatly deteriorated. During the follow-up period $27.7 \%$ $(15 / 54)$ sought additional psychological treatment; three participants had increased their medicine dosage, while six participants had lowered theirs.

The participants showed a reduction of symptoms after completing a tailored ICBT, and a majority of patients showed sustained effects at two years post-treatment. We did not investigate whether patients continuously used the treatment material or ingredients. That 15 patients sought additional treatment during the follow-up period might influence the follow-up data. However, these findings are not unexpected, given that many of the participants had experienced anxiety for a long period and many had undergone previous treatments. This study widens the usage of ICBT because it shows that tailoring treatment might be a feasible approach in treating anxiety disorders and addressing comorbidities. This is relevant since comorbidity is common among patients with anxiety disorders. 
Study II. Role of the working alliance on treatment outcome in tailored Internet-based cognitive behavioural therapy for anxiety disorders: Randomized controlled pilot trial

Aim

This study aimed to investigate possible correlations between clientrated working alliances (as measured pre-treatment, during the third week of treatment, and post-treatment) and treatment outcome in a group of patients with anxiety disorders receiving tailored ICBT.

\section{Methods}

Data for this study were collected from the treatment group $(n=27)$ in Study I (see Table 2 for demographic details).

CORE-OM served as the primary outcome measure (see also the method section presented for Study I), and alliance was measured using the short form of the Working Alliance Inventory (WAI-S; Hatcher \& Gillaspy, 2006), a 12-item process measure invented to measure working alliance on the three subscales (task, bond, and goal) and to provide an overall alliance score - that is, the total score (Horvath \& Greenberg, 1989). WAI-S exists in three versions: client-rated, therapist-rated, and observer-rated. For this study we used only the client-rated version, making minor modifications to the scale so as to fit the treatment format (i.e., the word treatment was changed to Internet treatment, and contact was changed to $e$ mail contact) and assessment point. In the first ratings, prior to any treatment, we made clear that participants' ratings would not affect their participation. The online version of WAI-S has shown excellent psychometric properties (Andersson et al., 2012).

In order to investigate the possible relationship between outcome and working alliance, we used bivariate correlations and multiple regression models. We calculated residual gain scores on COREOM through the formula $\mathrm{z} 2-(\mathrm{z} 1 * r 12)$, where $\mathrm{z} 2$ represents the $\mathrm{z}-$ transformed post-treatment CORE-OM raw score and $r 12$ is the Pearson correlation between pre- and post-treatment assessments. The residual gain score then served as the measurement of treatment outcome. Changes in alliance were tested by means of paired $t$-tests. 
Results and brief discussion

Alliance ratings increased from pre to mid-treatment $\left(t_{26}=5.5, p<\right.$ $.001)$ and there was a significant correlation between expected alliance and early alliance rating $(r=.57, p=.002, n=27)$.

WAI-S measured during the third week of treatment correlated significantly with CORE-OM post-treatment scores $(r=.47, p=.019$, $n=25)$. This correlation did not weaken when we controlled for expected working alliance $(\beta=.53, p=.027, n=25)$, and neither did history of psychological treatment $(\beta=.42, p=.039, n=25)$ or levels of symptoms $(\beta=.44, p=.036, n=25)$. Controlling for gender did cause the association to drop slightly $(\beta=.40, p=.058, n=$ 25).

Working alliance is considered important in treatments delivered face-to-face, having a moderate but robust effect on outcome (Horvath et al., 2011). There is evidence indicating that in ICBT outcome is enhanced by personal contact (Spek et al., 2007) and that the alliance ratings mirror the ratings in conventional treatment format (Knaevelsrud \& Maercker, 2007; Preschl et al., 2011). The participants in this study showed increased alliance ratings, indicating that ICBT does not lead to a weakened alliance. In this study we also found a significant correlation between alliance rating early in treatment and treatment outcome. This aligns with research suggesting that early alliance predicts lower levels of anxiety in cognitive therapy (Hoffart et al., 2012); however, the data on possible association between alliance and outcome in ICBT is mixed (Andersson et al., 2012; Knaevelsrud \& Maercker, 2006). 
Study III. Effectiveness and cost-effectiveness of individually tailored Internet-delivered cognitive behaviour therapy for anxiety disorders in a primary-care population: A randomized controlled trial

\section{Aim}

The aim of Study III was to investigate the effectiveness and costeffectiveness of the tailored ICBT programme for primary-care patients. Effects were investigated both post-treatment and at a oneyear follow-up.

\section{Methods}

The study was designed to be clinically representative (Shadish, Matt, Navarro, \& Phillips, 2000) in terms of recruitment, sample, therapists, and problems.

Inclusion was similar to that described for Study I. With some exceptions. Patients were recruited via their primary-care contact (GP, nurse, or counsellor), and if they were judged suitable for participation, they were given the address of the study website. The measurements and written consent procedure from Study I were used. A score of four or more on MADRS-S item 9 (suicidal thoughts) entailed further investigations; these applicants were contacted via telephone and interviewed by a psychiatrist using the SAD PERSONS scale (Patterson, Dohn, Bird, \& Patterson, 1983) and were excluded only if the clinical evaluation was that the participant showed an increased risk of suicidal attempts. If participants were judged suitable, they were contacted for a telephoneadministered SCID-I interview (First et al., 1997).

Of the 152 applicants, 100 were included from 18 different primarycare settings. A majority (58\%) reported at least one comorbid disorder, and $43 \%$ reported a comorbid mood disorder. For demographic details, see Table 2.

For the measurement of loss of production and health-care consumption, we used the Trimbos and Institute of Medical Technology Assessment Questionnaire on Costs Associated with Psychiatric Illness (TiC-P; Hakkaart-van Roijen \& Donker, 2002), 
and for the measurements of health-related quality of life, in order to estimate the cost of an additional quality-adjusted life year (QALY; Bravo Vergel \& Sculpher, 2008), we used EuroQol (EQ5D; EuroQol-Group, 1990).

Linear mixed models with an unstructured covariance structure were used to calculate treatment effects. Between- and within-group effect sizes were calculated using Cohen's $d$ by dividing the differences between estimated means and the pooled standard deviation (SD). SDs were converted from standard errors (SE) using the formula $\mathrm{SD}=\mathrm{SE}^{*} \sqrt{\mathrm{N}}$. Clinically significant improvement on COREOM was calculated with Jacobson and Truax's (1991) proposition of using reliable change index and cut-off scores from a nonclinical sample.

The incremental cost-effectiveness ratio (ICER) was estimated through the following formula: $\left(\Delta^{\mathrm{C} 1}-\Delta^{\mathrm{C} 2} / \Delta^{\mathrm{E} 1}-\Delta^{\mathrm{E} 2}\right)$. C1 - C2 is the differences in costs between ICBT and control condition, and E1 E2 is the difference in the average effectiveness of the two conditions (Drummond, Sculpher, Torrence, O'Brien, \& Stoddart, 2005). The costs considered were both medical and nonmedical. These procedures were bootstrapped 5000 times to generate reliable cost distribution estimates (Efron \& Tibshirani, 1993). Analyses were also conducted in which the costs of an additional QALY were calculated rather than those of an additional unit of primary outcome measure. In order to do this, we used the population-based index weights proposed by the EuroQol group (Dolan, 1997). A QALY of 1 is equivalent to one year of full health, and 0 equals death. The robustness of the results was tested in sensitivity analyses. The analyses were made to control how sensitive the ICERs would be to changes of estimated costs by increasing the costs for ICBT-both in a scenario with reduced productivity capacity owing to poorer treatment planning and in a scenario considering additional costs for programme development and implementation (e.g., low productivity owing to time spent on organizational matters). The latter were expected to be one-time costs. 
Between-group comparisons were performed only post-treatment because the control group crossed over to treatment after completing the post-treatment measures.

\section{Results and brief discussion}

Treatment effects

From pre- to post-treatment, effect sizes varied between $d=0.20$ and $d=0.86$, with a mean effect size of $d=0.59 .46 \%$ of the participants in the treatment condition showed clinically significant improvement on CORE-OM. Comorbid depression did not show any interaction effects on primary or secondary measures.

At the one-year follow-up, effects were sustained. Within-group effect sizes ranged from $d=0.53$ to $d=1.00$, with a mean effect size of $d=0.71$. 33.3\% (25/75) showed clinical significant improvement. Comorbid mood disorder did not moderate the effect on CORE-OM, BAI, or MADRS-S; however, there was a significant interaction effect of time and mood disorder on QOLI $(F(1,67.021)$ $=3.969, p=.023$ ) indicating that patients with comorbid depression had a larger gain in their life quality assessments from pre- to follow up measures.

At the one-year follow-up, $29.3 \%$ reported that they had started psychological treatment for their condition, and $13.6 \%$ reported having increased or having started medication. $76.3 \%$ reported no changes in medication (here not being on medication and not starting were counted as well), and $10.2 \%$ had lowered their dosages.

The drop-out rate in the treatment group was $6 \%(n=3)$, and two people were excluded. Eight participants withdrew their applications during the control condition, and during the treatment period of the control group, three participants dropped out, and two were excluded. $32 \%$ of the treatment group completed all prescribed modules within the ten weeks of treatment. On an average, participants mean completion rate were $53.5 \%$ of the prescribed modules.

Cost-effectiveness

From pre- to post-treatment, the ICBT group recorded a larger cost reduction than those in the control group, primarily driven by larger indirect cost reductions, and the cost-reduction was stable at the 
one-year follow-up. Each incremental improvement on CORE-OM in the treatment condition relative to control condition generated a societal earning of USD 1824 . And simulated ICERs indicate that ICBT is highly cost-effective compared to the control condition. Analyses when using the cost of an additional QALY revealed societal earnings of USD 7637 per one additional year. Simulated ICERs shows that the most probable outcome is that ICBT leads to additional QALYs while producing societal earnings.

Ten weeks of individually tailored ICBT were shown to be both effective and cost-effective for primary-care patients with a primary anxiety disorder. The treatment group reported greater improvements in anxiety, depression, and quality of life than those in the control group did. These improvements were maintained at the twelve-month follow-up. Analyses of costs and cost reduction showed that tailored ICBT was cost-effective. Together, these findings indicate that tailored ICBT might be a reasonable approach in treating primary-care patients with anxiety disorders and that it could be an economically viable alternative to other forms of treatment. That about one-third of the patients sought additional treatment might affect follow-up assessments, but it was no surprise since $64 \%$ had a history of psychological treatment for their condition. Because limited data is available on cost-effectiveness for ICBT, this study provides some evidence that tailored ICBT may be cost-effective without decreasing clinical effects. 


\section{General Discussion}

\section{Main findings and conclusions}

The aims of this thesis were to explore the effects of tailoring the internet-based cognitive behavioural therapy to meet preferences and characteristics of patients with a primary anxiety disorders. In order to fulfil this, two randomised controlled trials were designed. The first was an efficacy trial, with a self-recruited sample, and the second a clinical effectiveness trial, with patients recruited from primary-care settings. In order to get a fuller picture we included both long-term outcomes, process measures (e.g., working alliance measurements) and cost-effectiveness analysis.

Results from the first randomised controlled trial (i.e., Study I and II) indicated that patients suffering from anxiety disorders, with or without comorbidity, did benefit from this tailored ICBT treatment. Moreover, treatment effects were sustained two years after the end of treatment. It seems that working alliance rated by the participants early in treatment (at week three) affected the outcome using our protocol (Study II). Even if this correlation is revealed in a small sample, and the study has its limitations, this is of interest since this association has rarely been found in studies using single ICBT protocols.

In relation to the second area of interest in this thesis, the effectiveness of the tailored protocol, Study III showed that effects found in the self-recruited sample from the first randomised controlled trial was replicated when using a sample recruited through primary-care. The effects were sustained at one year follow-up and costeffectiveness analysis proved superiority of the treatment compared to a control condition. These results underscore that ICBT can be used in real life settings with favourable results.

Many patients who suffer from anxiety disorders show a chronic course without treatment. Even if receiving adequate treatment and showing beneficial post-treatment and six-month or one-year follow-up effects, at longer-term follow-up many still meet the criteria 
for a diagnosis. Many also feel the need of seeking further treatment for their problems. At what point is the new learning diminished by old learning, and how could we make therapy more effective and long lasting? One way to make therapy more effective might be through the possibilities that ICBT offers of downloading and printing treatment materials, as well as of online correspondence with the therapist. This may not prevent recurrence, but it might be helpful in that the patient could more easily make use of earlier learned approaches in order to handle similar feelings and problems and need not to rely on making an appointment with a therapist to remind him- or herself of previously achieved skills for managing anxiety-evoking events.

\section{Why the good results in ICBT?}

Perhaps the good results for ICBT are no surprise. CBT and ICBT share important features, and CBT has proved to be an effective treatment of anxiety disorders for over forty years (Öst, 2008). Similarities have been shown regarding the therapeutic relationship, indicating that an online relationship is formed and could be important as is the cease in conventional psychotherapies. ICBT has the advantages of allowing the patient to plan her or his own time rather than complying with the opening hours of a clinic, leaving more room for accommodating patient preferences.

In conventional CBT for anxiety disorders, a rather strict treatment protocol is often used, including exposure with hierarchy, in which the patient and the therapist work together during the first exposure sessions. This results in a rather "clean" exposure, in not doing anything that can be seen as too difficult, or in using a habituation paradigm in which the exposure continues until a decrease in anxiety is achieved. In ICBT, on the other hand, the patient is in charge of the exposures, perhaps rendering a more naturalistic exposure to the feared situations - not necessarily taking one stimulus at a time but going "all in," making it possible to more efficiently learn new behaviours in a greater variety of situations. This has been suggested as one possible way to reduce relapses (Bouton, 2002). Regarding the possible benefits of having a therapist present during exposure sessions, research has shown that for patients with obsessive-compulsive disorders, therapist- and self-controlled exposure 
in vivo are equally effective post-treatment, and the effects are sustained at follow-up three and a half months later (Emmelkamp \& Kraanen, 1977). Possibly the patient is more accurately approaching earlier avoided contexts (accurate in the sense of being relevant to the patient's life), leading to new behaviours and new contingences of reinforcement that moderate the effects of exposure more beneficially than therapist-led exposure does. This might reduce the recurrence of symptoms, for self-administrated exposure might facilitate exposure in many different settings, possibly of longer duration and of a greater variety in the anxiety experienced during exposure.

It is also possible that conventional CBT for anxiety might frighten patients when presented as exposure therapy, especially considering the heavy emphasis on the importance of dropping all safety behaviours, which the patient often views as lifesaving. Of course, this is presented as important during the psychoeducation in the first modules of the ICBT treatment as well, and safety behaviours can be anti-therapeutic because they stop the occurrence of disconfirming experiences (Salkovskis, 1991). But allowing some safety behaviours, at least initially, might help patients to agree to and to start exposure therapy, as well as to stay in the feared situation for a longer time, thus facilitating the treatment (Rachman, Radomsky, \& Shafran, 2008). Moroeover, there is now evidence that exposure therapy might still be effective (Rachman, Shafran, Radomsky, \& Zysk, 2011), even when some safety behaviours are included. In ICBT, participants are not controlled by their therapists in terms of the extent that they let go of their safety behaviours during exposure. This may facilitate patients' willingness to actually start treatment and to make the behavioural changes necessary for improvements to occur.

\section{Representativity of the samples}

A critical issue is if the samples in the included ICBT studies are representative for regular patients seen in clinic. Of the participants, $76 \%$ were employed or students. In Study I, 41\% reported a completed university education as their highest level of education. In Study III the percentage was identical. According to public statistics in Sweden, this is a figure similar to that among the general popula- 
tion, in which $38 \%$ of citizens between 25 and 64 years old are registered as having completed some form of tertiary education (Statistics Sweden [SCB], 2011). The study samples included ages ranging from 22 to 63, with a mean age of 38.8 years (Study I), and from 19 to 68, with a mean age of 35.3 years (Study III). This gives approximately the same age span as in the SCB study and approximately the same educational level as well. The participants with ongoing medication constitute approximately $26 \%$ of both samples, and the percentages of patients with a history of medical $(33 \%$ vs. $31 \%$ ) and psychological (42.5\% vs. $64 \%$ ) treatment resemble a clinical population. Comorbidity levels $(50 \%$ in Study I and $58 \%$ in Study III) also align with the data on comorbidity in individuals with anxiety disorders. Overall, it seems that the samples are representative of the general population when it comes to educational level and of a more clinical population regarding medication, previous treatment, and comorbidities.

\section{Drop-out rates}

Comparing drop-out rates between Study I, including a selfrecruited sample and the effectiveness study (Study III), revealed that no one dropped out of Study I during treatment, while 3 of the $50(6 \%)$ in the treatment group dropped out of Study III. This suggests that the treatment was acceptable to the participants. However, not all participants completed their prescribed modules within the given time frame. In Study I, 59\% (16 of 24) completed all prescribed modules, while $32 \%$ (16 of 50) in Study III completed theirs, indicating room for improvement. As Eysenbach (2005) stated, this phenomenon can be considered a form of passive drop-out. Not all the included participants completed follow-up questionnaires. In Study I, which started with a total of 54 participants, data was collected from 52 at post-treatment, 51 at the one-year followup, and 44 at the two-year follow-up. In Study III, of the 100 included participants, 91 provided post-treatment data, and 76 participants answered the questionnaires at the one-year follow-up. This was addressed by using intention to treat analyses, by following the advice of publishing drop-out rates, and by handling them via statistical analyses (Christensen \& Mackinnon, 2006; Eysenbach, 2005). In this way data can still provide important information. 
Drop-out and adherence rates in our studies align with those in previous research. For example, Newby et al. (2013) presented adherence rates of $41 \%$ for a sample with mixed anxiety and depression. These figures should be seen in the light of the finding that in conventional anxiety treatments, drop-out has been shown to be $50 \%$ or more (Santana \& Fontenelle, 2011).

If we were to implement this tailored treatment protocol in regular care, the research community would benefit from both the evidence of the treatment's effectiveness and from the research done on the implementation of large-scale projects using computerized CBT programmes and guided self-help. The research on hindrances in implementation and on how to increase adherence in our programmes would especially useful. Following conclusions from Clough and Casey (2011), it is possible to add extra reminders by email or telephone to the programmes, preferably with interactive components, such as electronic homework tasks administered via smartphones. Hilvert-Bruce et al. (2012) suggested that apart from added reminders, adherence improves by adding choice of course, financial cost, and clinician contact during the course. All suggestions for reminders or prompts must, of course, be guided by the patient's own informed consent.

\section{Comparing single and tailored protocols}

In a meta-analysis by Andrews et al. (2010), the mean effect size of single protocol ICBT over the control group was $d=0.88$. This was corroborated by the findings in Lewis et al. (2012), who reported an effect size of 0.88 in favour of single protocols over a waiting list. In Study I the between-group effect size on the primary outcome measure (CORE-OM) was 1.00, and the mean effect size was 0.69. In Study III the mean between-group effect size was 0.59 and 0.86 on CORE-OM. One possible reason for the slightly lower effect sizes presented for the tailored protocols used in our studies is that we did not use a passive waiting list as a control condition. The online discussion forum used in Study I and the weekly e-mail messages used in Study III are more similar to an attention placebo, and therefore the comparison is not straightforward. In a comparison of tailored ICBT and standardized single protocol ICBT and waitlist for depression and comorbid symptoms in a self-recruited sample, 
no differences were seen between treatments at post-treatment or at the six-month follow-up (Johansson et al., 2012). Sub group analyses however revealed that patients with more severe depression and comorbidity benefitted more from the tailored treatment than the single protocol treatment. Possibly effects are similar for patients with a primary anxiety disorder. The patients in our studies reported suffered from anxiety for a long period of time (mean years with distress; Study I, 14.1 yrs.; and Study III, 10.3 yrs.), if viewing comorbidity as a representation of more severe anxiety problems, this might also be valid in our studies.

Since the research on tailored protocols is sparse, it may not be the time now to abandon gold-standard protocols. Instead, as suggested by Bauer et al. (2012), perhaps the primary anxiety disorder should be targeted first; then tailoring treatment or using a unified protocol would be plausible later.

\section{Enduring effects of the tailored protocol}

It seems that our tailored study protocols, besides being beneficial at post-treatment, are efficacious up to two years after treatment ends. Considering the definitions by Hollon et al. (2006), the treatment could possibly be viewed as curative, reversing the underlying processes that contribute to the disorders' continuation. By reversing the process, I mean learning more adaptive ways of dealing with feelings of fear and anxiety and being able to take preferred action without using escape automatically in formerly anxiety-inducing situations.

\section{Limitations}

There are limitations to this thesis, among them the limitation in all three studies that for comparison we did not have another treatment, but only an attention placebo. This allows us to answer questions only regarding whether tailored ICBT treatment is more effective than the control condition was concerning symptom reduction and improved quality of life, and (in Study III) whether the treatment is cost-effective. Comparing our treatment protocol to conventional face-to-face CBT-treatment, a single CBT-protocol, or other active 
treatments would have been interesting, specifically in the effectiveness study, in order to collect more representative data.

Another limitation is the lack of weekly measurements, which leaves us with no possibility other than guessing whether the patients who dropped out of treatment or stopped writing in their homework assignments did so because they felt better, worse, or the same or did not find the treatment as interesting and beneficial as they had expected. If measures had been taken weekly, we would also have had more reliable data to add to the dataset for the missing values, even if we still used the last observation carried forward. Weekly measurements would also have helped us answer questions regarding processes - for example, how the alliance changes during treatment in Study II, whether patients who benefit from ICBT treatment differ in any way on the self-rating scales from patients who do not, and whether drop-outs were preceded by heightened or lowered symptom severity.

Another limitation shared by Studies I and III is the selection of modules. The selections were based on SCID-protocols and to some extent on patient preferences, not on a functional analysis or a case conceptualization, often standard in conventional CBT; this might have resulted in a different order and different content for the treatment.

Study I and to a greater extent Study II, which used the treatment group from Study I, suffer from the small sample size, which limits the opportunity to draw conclusions from data and to further explore possible differences (e.g., gender in Study II).

\section{Future directions}

This thesis has only just started investigating the possible use of a tailored ICBT treatment protocol for patients suffering from anxiety disorders. Hopefully, the interest in this topic will not end here. Further research could highlight the processes of making treatments effective (i.e., mediators and moderators). This is one way of shedding light on and help reveal the individual factors that affect 
treatment outcome, and therefore it should influence into decisions about how to tailor treatments. Mediators, answering questions regarding how treatment works, would possibly help us understand in what way specific parts contribute to treatment. They would perhaps also shed light on the nature of clinical psychological distress (Kraemer, Wilson, Fairburn \& Agras, 2002).

CBT is widely regarded as an evidence-based treatment, and it is the psychological treatment of choice for anxiety disorders according to Swedish National Board of Health and Welfare. A large proportion of the patients that suffers from mild to moderate psychiatric conditions are to be treated in the first line of psychiatrythat is, primary care - and consideration of the implementation of IAPT in the United Kingdom causes one to wonder if Swedish health care could reap the same benefits. For mild to moderate anxiety disorders, NICE recommendations entail low-intensity treatments as a first step. This may be a feasible approach even in Sweden, given the advantages that evidence-based treatments already exist and that platforms are ready to use if politicians are willing to decide upon and pay for the implementation. Some places in Sweden already administer ICBT on a regular basis. For example the Internet psychiatry unit in Stockholm has been doing so since 2007, and research using data from patients suffering from panic disorder (Hedman et al., 2013) and depression (Hedman et al., in press) treated via the unit indicates successful outcomes.

Even if evidence-based treatment platforms exist, they are not available in regular primary care, at least not in Sweden. The Swedish Association of Local Authorities and Regions recently presented a report on how to implement ICBT in regular care (Swedish Association of Local Authorities and Regions, 2013) and on the possible benefits of ICBT in that arena, after nearly 15 years of research on the matter. This report shows the potential of ICBT in regular care, but most studies included in the report lack costeffectiveness studies. Another limitation might be that allegiance is high - the same person or persons who developed the treatment programmes also investigated its effects. This is true both of the treatments developed in research settings with no economic interests and of the programmes developed in private practices that have 
economic interests in their product. In the future, hopefully each group will test the other's programmes in order to investigate whether or not the results would be replicated.

Making use of ICBT in regular care might also ensure the quality of administered treatments by decreasing the risk of therapists drifting away from effective treatment protocols that may cause diluted effects of well-researched, gold-standard treatment protocols. Regarding how these protocols are to be designed in the future, only more research can answer questions regarding whether tailored treatment, or transdiagnostic approaches, would benefit those affected by anxiety disorders with or without comorbidities.

Further research along the lines of that presented in this thesis should implement the tailored programme fully in a primary-care setting. To expand the usability of the treatment protocol it would be of interest to include modules that address somatic problems since this is a common concern in patients experiencing anxiety disorders in this context. Future research should emphasize treatment effectiveness, cost-effectiveness, and patient and provider satisfaction with the programme, as well as how difficult or easy it is for therapists to master. It is of great value to attempt to gain a complete picture of patients' and providers' perspectives, as well as an economic perspective, in order to argue for the broad implementation of this kind of treatment that will further improve evidencebased practice in primary-care settings - for the good of the patient. 


\section{REFERENCES}

Abramowitz, J. S. (2013). The practice of exposure therapy:

Relevance of cognitive-behavioral theory and extinction theory. Behavior Therapy, 44, 548-558.

Almlöv, J., Carlbring, P., Berger, T., Cuijpers, P., \& Andersson, G. (2009). Therapist factors in Internet-delivered cognitive behavioural therapy for major depressive disorder. Cognitive Behaviour Therapy, 38, 247-254.

Alonso, J., Angermeyer, M. C., Bernert, S., Bruffaerts, R., Brugha, T. S., Bryson, H., . . . EsemeD/Mhedea Investigators, E. S. o. t. E. o. M. D. P. (2004a). Prevalence of mental disorders in Europe: results from the European Study of the Epidemiology of Mental Disorders (ESEMeD) project. Acta Psychiatrica Scandinavica. Supplementum, 109, 21-27.

Alonso, J., Angermeyer, M. C., Bernert, S., Bruffaerts, R., Brugha, T. S., Bryson, H., . . . Almansa, J. (2004b). 12-Month comorbidity patterns and associated factors in Europe: results from the European Study of the Epidemiology of Mental Disorders (ESEMeD) project. Acta Psychiatrica Scandinavica, 109, 28-37.

American Psychiatric Association. (2000). Diagnostic and statistical manual of mental disorders - Text Revision (4 ed.). Washington, DC, USA: American Psychiatric Press. American Psychiatric Association. (2013a). Diagnostic and Statistical Manual of Mental Disorders. Fifth edition. (5th ed.). Washington DC: American Psychiatric Publishing. American Psychiatric Association. (2013b, may 17, 2013).

Highlights of Changes from DSM-IV-TR to DSM-5, 2013, from http://www.psychiatry.org/dsm5

Andersson, G., Bergström, J., Buhrman, M., Carlbring, P., Holländare, F., Kaldo, V., . . . Waara, J. (2008).

Development of a new approach to guided self-help via the Internet. The Swedish experience. Journal of Technology and Human Services., 26, 161-181. 
Andersson, G., Carlbring, P., Holmstrom, A., Sparthan, E., Furmark, T., Nilsson-Ihrfelt, E., . . Ekselius, L. (2006).

Internet-based self-help with therapist feedback and in vivo group exposure for social phobia: a randomized controlled trial. Journal of Consulting and Clinical Psychology, 74, 677-686.

Andersson, G., Cuijpers, P., Carlbring, P., Riper, H., \& Hedman, E. (In press). Internet-based vs. face-to-face cognitive behaviour therapy for psychiatric and somatic disorders: a systematic review and meta-analysis. World Psychiatry. Andersson, G., Paxling, B., Wiwe, M., Vernmark, K., Felix, C. B., Lundborg, L., . . Carlbring, P. (2012). Therapeutic alliance in guided internet-delivered cognitive behavioural treatment of depression, generalized anxiety disorder and social anxiety disorder. Behaviour Research and Therapy, 50, 544550 .

Andrews, G., Cuijpers, P., Craske, M. G., McEvoy, P., \& Titov, N. (2010). Computer Therapy for the Anxiety and Depressive Disorders Is Effective, Acceptable and Practical Health Care: A Meta-Analysis. PLoS ONE, 5(10). e13196 Andrusyna, T. P., Tang, T. Z., DeRubeis, R. J., \& Luborsky, L. (2001). The factor structure of the working alliance inventory in cognitive-behavioral therapy. Journal of Psychotherapy Practice and Research, 10, 173-178. Arch, J. J., \& Craske, M. G. (2011). Addressing Relapse in Cognitive Behavioral Therapy for Panic Disorder: Methods for Optimizing Long-Term Treatment Outcomes. Cognitive and Behavioral Practice, 18, 306-315.

Baardseth, T. P., Goldberg, S. B., Pace, B. T., Wislocki, A. P., Frost, N. D., Siddiqui, J. R., . . Wampold, B. E. (2013). Cognitive-behavioral therapy versus other therapies: Redux. Clinical Psychology Review, 33, 395-405.

Baldwin, D. S., Anderson, I. M., Nutt, D. J., Bandelow, B., Bond, A., Davidson, J. R. T., ... Wittchen, H. U. (2005). Evidence-based guidelines for the pharmacological treatment of anxiety disorders: Recommendations from the British Association for Psychopharmacology. Journal of Psychopharmacology, 19, 567-596. 
Baldwin, J. D., \& Baldwin, J. I. (2001). Behavior principles in everyday life (4th ed.). Upper Saddler River: Pearson Education.

Baldwin, S. A., Wampold, B. E., \& Imel, Z. E. (2007). Untangeling the alliance-outcome correlation: Exploring the relative importance of therapist and patient variability in the alliance. Journal of Consulting and Clinicala Psychology, 842-852.

Barkham, M., Margison, F., Leach, C., Lucock, M., Mellor-Clark, J., Evans, C., . . McGrath, G. (2001). Service profiling and outcomes benchmarking using the CORE-OM: Toward practice-based evidence in the psychological therapies. Journal of Consulting and Clinical Psychology, 69, 184196.

Barlow, D. H. (1991). Disorders of emotion. Psychological Inquiry, 2(1), 58-71.

Barlow, D. H. (Ed.). (2002). Anxiety and its disorders: The nature and treatment of anxiety and panic (2nd ed.). New York, NY, US: Guilford Press.

Barlow, D. H., Allen, L. B., \& Choate, M. L. (2004). Toward a unified treatment for emotional disorders. Behavior Therapy, 35, 205-230.

Barlow, D. H., Bullis, J. R., Comer, J. S., \& Ametaj, A. A. (2013). Evidence-based psychological treatments: An update ans a way forward. Annual Review of Clinical Psychology, 9, 127.

Bauer, I., Wilansky-Traynor, P., \& Rector, N. A. (2012). Cognitivebehavioral therapy for anxiety disorders with comorbid depression: A review. International Journal of Cognitive Therapy, 5, 118-156.

Beck, A. T. (1979). Cognitive therapy and the emotional disorders. New York: Meridian Book.

Beck, A. T., Epstein, N., Brown, G., \& Steer, R. A. (1988). An inventory for measuring clinical anxiety: psychometric properties. Journal of Consulting and Clinical Psychology, 56, 893-897. 
Bell, C. J., Colhoun, H. C., Carter, F. A., \& Frampton, C. M. (2012). Effectiveness of computerised cognitive behaviour therapy for anxiety disorders in secondary care. Australian and New Zealand Journal of Psychiatry, 46, 630-640.

Berger, T., Boettcher, J., \& Caspar, F. (In press) Internet-based guided self-help for several anxiety disorders: A randomized controlled trial comparing a tailored with a standardized disorder-specific program. Psychotherapy.

Bohart, A. C., \& House, R. (2009). Empirically supported/validated treatmnents as modernist ideology,I:Dodo, manualization, and the paradigm Question. In R. House \& D. Loewenthal (Eds.), Against and for CBT: Towards a consturctive dialogue? (pp. 188-201). Ross-on-wye: PCCS BOOKS.

Bordin, E. S. (1979). The generalizability of the psychoanalytic concept of the working alliance. Psychotherapy: Theory, Research \& Practice, 16, 252-260.

Bouton, M. E. (2002). Context, ambiguity, and unlearning: Sources of relapse after behavioral extinction. Biological Psychiatry, 52, 976-986.

Bouton, M. E. (2007). Learning and behavior: A contemporary synthesis Sunderland, MA: Sinauer Associates.

Bouton, M. E., Mineka, S., \& Barlow, D. H. (2001). A modern learning theory perspective on the etiology of panic disorder. Psychological Review, 108, 4-32.

Bravo Vergel, Y., \& Sculpher, M. (2008). Quality-adjusted life years. Practical Neurology, 8, 175-182.

Brown, T. A., Campbell, L. A., Lehman, C. L., Grisham, J. R., \& Mancill, R. B. (2001). Current and lifetime comorbidity of the DSM-IV anxiety and mood disorders in a large clinical sample. Journal of Abnormal Psychology, 110, 585-599.

Bruce, S. E., Yonkers, K. A., Otto, M. W., Eisen, J. L., Weisberg, R. B., Pagano, M., .. . Keller, M. B. (2005). Influence of psychiatric comorbidity on recovery and recurrence in generalized anxiety disorder, social phobia, and panic disorder: a 12-year prospective study. The American journal of psychiatry, 162, 1179-1187. 
Butler, A. C., Chapman, J. E., Forman, E. M., \& Beck, A. T. (2006). The empirical status of cognitive-behavioral therapy: a review of meta-analyses. Clinical Psychology Review, 26, 17-31.

Campbell-Sills, L., Sherbourne, C. D., Roy-Byrne, P., Craske, M.

G., Sullivan, G., Bystritsky, A., . . Stein, M. B. (2012).

Effects of co-occuring depression on treatment for anxiety disorders: Analysis of outcome from a large primary care effectiveness trial. Journal of Clinical Psychiatry, 73, 15091516.

Carlbring, P., Bohman, S., Brunt, S., Buhrman, M., Westling, B. E., Ekselius, L., \& Andersson, G. (2006). Remote treatment of panic disorder: a randomized trial of internet-based cognitive behavior therapy supplemented with telephone calls. American Journal of Psychiatry, 163, 2119-2125.

Carlbring, P., Gustafsson, H., Ekselius, L., \& Andersson, G. (2002). 12-month prevalence of panic disorder with or without agoraphobia in the Swedish general population. Social Psychiatry and Psychiatric Epidemiology, 37, 207-211. Carlbring, P., Nordgren, L. B., Furmark, T., \& Andersson, G. (2009). Long-term outcome of Internet-delivered cognitivebehavioural therapy for social phobia: a 30-month followup. Behaviour Research and Therapy, 47, 848-850.

Christensen, H., \& Mackinnon, A. (2006). The law of attrition revisited. Journal of Medical Internet Research, 8, e20; author reply e21.

Clark, D. M., Layard, R., Smithies, R., Richards, D. A., Suckling, R., \& Wright, B. (2009). Improving access to psychological therapy: Initial evaluation of two UK demonstration sites. Behaviour Research and Therapy, 47, 910-920.

Clough, B. A., \& Casey, L. M. (2011). Technological adjuncts to increase adherence to therapy: A review. Clinical Psychology Review, 31, 697-710.

Cook, J. E., \& Doyle, C. (2002). Working alliance in Online therapy as compared to face-to-face therapy: Preliminary results. Cyberpsychology and Behavior, 5, 95-105.

Coull, G., \& Morris, P. G. (2011). The clinical effectiveness of CBT-based guided self-help interventions for anxiety and 
depressive disorders: a systematic review. Psychological Medicine, 41, 2239-2252.

Craske, M. G. (2012). Transdiagnostic treatment for anxiety and depression. Depression and Anxiety, 29, 749-753.

Craske, M. G., Kircanski, K., Zelikowsky, M., Mystkowski, J., Chowdhury, N., \& Baker, A. (2008). Optimizing inhibitory learning during exposure therapy. Behaviour Research and Therapy, 46, 5-27.

Craske, M. G., Rauch, S. L., Ursano, R., Prenoveau, J., Pine, D. S., \& Zinbarg, R. E. (2009). What is an anxiety disorder? Depression and Anxiety, 26, 1066-1085.

Craske, M. G., Rose, R. D., Lang, A., Welch, S. S., Campbell-Sills, L., Sullivan, G., . . Roy-Byrne, P. P. (2009). Computerassisted delivery of cognitive behavioral therapy for anxiety disorders in primary-care settings. Depression and Anxiety, 26, 235-242.

Craske, M. G., Stein, M. B., Sullivan, G., Sherbourne, C., Bystritsky, A., Rose, R. D., . . Roy-Byrne, P. (2011). Disorder-specific impact of coordinated anxiety learning and management treatment for anxiety disorders in primary care. Archives of General Psychiatry, 68, 378-388.

Cuijpers, P., Donker, T., Li, J., \& Andersson, G. (2010). Is guided self-help as effective as face-to-face psychotherapy for depression and anxiety disorders? A systematic review and meta-analysis of comparative outcome studies.

Psychological Medicine,40, 1943-1957.

Cuijpers, P., Marks, I. M., van Straten, A., Cavanagh, K., Gega, L., \& Andersson, G. (2009). Computer-aided psychotherapy for anxiety disorders: a meta-analytic review. Cognitive Behaviour Therapy, 38, 66-82.

Curran, G. M., Sullivan, G., Mendel, P., Craske, M. G., Sherbourne, C. D., Stein, M. B., . . Roy-Byrne, P. (2012).

Implementation of the CALM intervention for anxiety disorders: a qualitative study. Implementation Science, 7, 111.

Dear, B. F., Titov, N., Schwencke, G., Andrews, G., Johnston, L., Craske, M. G., \& McEvoy, P. (2011). An open trial of a brief transdiagnostic internet treatment for anxiety and depression. Behaviour Research and Therapy, 49, 830-837. 
Denollet, J., Maas, K., Knottnerus, A., Keyzer, J. J., \& Pop, V. J. (2009). Anxiety predicted premature all-cause and cardiovascular death in a 10-year follow-up of middle-aged women. Journal of Clinical Epidemiology, 62, 452-456.

Dolan, P. (1997). Modeling valuations for EuroQol health states. Medical Care, 35, 1095-1108.

Drummond, M. F., Sculpher, M. J., Torrence, G. W., O'Brien, B. J., \& Stoddart, G. L. (2005). Methods for the evaluation of health care programmes. Oxford: Oxford University Press.

Dunsmoor, J. E., Prince, S. E., Murty, V. P., Kragel, P. A., \& LaBar, K. S. (2011). Neurobehavioral mechanisms of human fear generalization. Neuroimage, 55, 1878-1888.

Durham, R. C., Chambers, J. A., Power, K. G., Sharp, D. M., Macdonald, R. R., Major, K. A., ... Gumley, A. I. (2005). Long-term outcome of cognitive behaviour therapy clinical trials in central Scotland. Health technology assessment (Winchester, England), 9, 1-174.

Durham, R. C., Higgins, C., Chambers, J. A., Swan, J. S., \& Dow, M. G. (2012). Long-term outcome of eight clinical trials of CBT for anxiety disorders: symptom profile of sustained recovery and treatment-resistant groups. Journal of Affective Disorders, 136, 875-881.

Efron, B., \& Tibshirani, R. J. (1993). An introduction to the bootstrap. New York: Chapman \& Hall.

Emmelkamp, P. M. G., \& Kraanen, J. (1977). Therapist-controlled exposure in vivo versus self-controlled exposure in vivo: A comparison with obsessive-compulsive patients. Behaviour Research and Therapy, 15, 491-495.

EuroQol-Group. (1990). EuroQol - a new facility for the measurement of health-related quality of life. Health Policy, 16, 199-208.

Eysenbach, G. (2005). The law of attrition. Journal of Medical Internet Research, 7, e11.

Fichter, M. M., Quadflieg, N., Fischer, U. C., \& Kohlboeck, G. (2010). Twenty-five-year course and outcome in anxiety and depression in the Upper Bavarian Longitudinal Community Study. Acta Psychiatrica Scandinavica,122, 75-85. 
First, M. B., Gibbon, M., Spitzer, R. L., \& Williams, J. B. W. (1997). Structured clinical interview for DSM-IV Axis I Disorders (SCID-I). Washington, D.C.: American Psychiatric Press.

Flückiger, C., Del Re, A. C., Wampold, B. E., Symonds, D., \& Horvath, A. O. (2012). How central is the alliance in psychotherapy? A multilevel longitudinal meta-analysis. Journal of Counseling Psychology, 59, 10-17.

Frisch, M. B., Cornell, J., Villanueva, M., \& Retzlaff, P. J. (1992). Clinical validation of the Quality of Life Inventory. A measure of life satisfaction for use in treatment planning and outcome assessment. Psychological Assessment, 4, 92-101. Furmark, T., Tillfors, M., Everz, P. O., Marteinsdottir, I., Gefvert, O., \& Fredrikson, M. (1999). Social phobia in the general population: Prevalence and sociodemographic profile. Social Psychiatry and Psychiatric Epidemiology, 34, 416-424.

Garber, A. M., Weinstein, M. C., Torrence, G. W., \& Kamlet, M. S. (1996). Theoretical foundations of cost-effectiveness analysis. In M. R. Gold, J. E. Siegel, L. B. Russel \& M. C. Weinstein (Eds.), Cost-effectiveness in health and medicine. (pp. 25-53). New York: Oxford university press.

Guy, W. (1976). Clinical Global Impressions. ECDEU assessment manual for psychopharmacology, us department of health and human services (pp. 217-222). Rockville: NIMH.

Hakkaart-van Roijen, L., \& Donker, M. C. H. (2002).

Manual/iMTA questionnaire for costs associated with psychiatric illness (TIC-P), from http://hdl.handle.net/1765/1337

Hall, A. M., Ferreira, P. H., Maher, C. G., Latimer, J., \& Ferreira, M. L. (2010). The influence of the therapist-patient relationship on treatment outcome in physical rehabilitation: a systematic review. Physical Therapy, 90, 1099-1110.

Hans, E., \& Hiller, W. (2013). A meta-analysis of nonrandomized effectiveness studies on outpatient cognitive behavioral therapy for adult anxiety disorders. Clinical Psychology Review, 33, 954-964.

Hatcher, R. L., \& Gillaspy, J. A. (2006). Development and validation of a revised short version of the Working Alliance Inventory. Psychotherapy Research, 16, 12-25. 
Hedman, E., Furmark, T., Carlbring, P., Ljotsson, B., Ruck, C., Lindefors, N., \& Andersson, G. (2011). A 5-Year Follow-up of Internet-Based Cognitive Behavior Therapy for Social Anxiety Disorder. Journal of Medical Internet Research, 13, e39.

Hedman, E., Ljótsson, B., Kaldo, V., Hesser, H., El Alaoui, S., Kraepelin, M., Andersson, E., Rück, C., Svanborg, C., Andersson, G., \& Lindefors, N. (In press). Effectiveness of Internet-based cognitive behaviour therapy for depression in routine psychiatric care. Journal of Affective Disorders.

Hedman, E., Ljótsson, B., \& Lindefors, N. (2012). Cognitive behavior therapy via the Internet: a systematic review of applications, clinical efficacy and cost-effectiveness. Expert Review of Pharmacoeconomics and Outcomes Research, 12, 745-764.

Hedman, E., Ljótsson, B., Rück, C., Bergström, J., Andersson, G., Kaldo, V., . . . Lindefors, N. (In press). Effectiveness of Internet-based cognitive behaviour therapy for panic disorder in routine psychiatric care. Acta Psychiatrica Scandinavica.

Hendriks, S. M., Spijker, J., Licht, C. M., Beekman, A. T., \& Penninx, B. W. (2012). Two-year course of anxiety disorders: different across disorders or dimensions? [Journal article]. Acta Psychiatrica Scandinavica.

Hettema, J. M. (2008). What is the genetic relationship between anxiety and depression? American Journal of Medical Genetics. Part C, Seminars in Medical Genetics, 148C, 140146.

Hilvert-Bruce, Z., Rossouw, P. J., Wong, N., Sunderland, M., \& Andrews, G. (2012). Adherence as a determinant of effectiveness of internet cognitive behavioural therapy for anxiety and depressive disorders. Behaviour Research and Therapy, 50, 463-468.

Hoffart, A., Borge, F. M., Sexton, H., Clark, D. M., \& Wampold, B. E. (2012). Psychotherapy for social phobia: how do alliance and cognitive process interact to produce outcome? Psychother Res, 22, 82-94. 
Hofmann, S. G., Asnaani, A., Vonk, I. J. J., Sawyer, A. T., \& Fang, A. (2012). The Efficacy of cognitive behavioral therapy: A review of meta-analyses Cognitive Therapy Research, 427440.

Hoifodt, R. S., Strom, C., Kolstrup, N., Eisemann, M., \& Waterloo, K. (2011). Effectiveness of cognitive behavioural therapy in primary health care: a review. Family Practice, 28, 489-504.

Hollon, S. D., Stewart, M. O., \& Strunk, D. (2006). Enduring effects for cognitive behavior therapy in the treatment of depression and anxiety. Annual Review of Psychology, 57, 285-315.

Horvath, A. O., Del Re, A. C., Fluckiger, C., \& Symonds, D. (2011). Alliance in individual psychotherapy. Psychotherapy (Chic), 48, 9-16.

Horvath, A. O., \& Greenberg, L. S. (1989). Development and Validation of the Working Alliance Inventory. Journal of Counseling Psychology, 36, 223-233.

Horvath, A. O., \& Symonds, B. D. (1991). Relation between working alliance and outcome in psychotherapy: A metaanalysis. Journal of Counseling Psychology, 38, 139-149.

Jacobson, N. S., \& Truax, P. (1991). Clinical significance: A statistical approach to defining meaningful change in psychotherapy research. Journal of Consulting and Clinical Psychology, 59, 12-19.

Johansson, R., Carlbring, P., Heedman, Å., Paxling, B., \& Andersson, G. (2013). Depression, anxiety and their comorbidity in the Swedish general population: Point prevalence and the effect on health-related quality of life. PeerJ, 1, e98.

Johansson, R., Sjöberg, E., Sjögren, M., Johnsson, E., Carlbring, P., Andersson, T., . . . Andersson, G. (2012). Tailored vs. standardized internet-based cognitive behavior therapy for depression and comorbid symptoms: a randomized controlled trial. PLoS ONE, 7, e36905.

Johnston, L., Titov, N., Andrews, G., Spence, J., \& Dear, B. F. (2011). A RCT of a transdiagnostic internet-delivered treatment for three anxiety disorders: examination of support roles and disorder-specific outcomes. PLoS ONE, 6, e28079. 
Kessler, R. C., Berglund, P., Demler, O., Jin, R., \& Walters, E. E. (2005). Lifetime prevalence and age-of-onset distributions of DSM-IV disorders in the national comorbidity survey replication. Archives of General Psychiatry,62, 539-602.

Knaevelsrud, C., \& Maercker, A. (2006). Does the quality of the working alliance predict treatment outcome in online psychotherapy for traumatized patients? Journal of Medical Internet Research, 8(4), e31.

Knaevelsrud, C., \& Maercker, A. (2007). Internet-based treatment for PTSD reduces distress and facilitates the development of a strong therapeutic alliance: a randomized controlled clinical trial. BMC Psychiatry, 7, 13.

Kraemer, H. C., Wilson, G. T., Fairburn, C. G., \& Agras, W. S. (2002). Mediators and moderators of treatment effects in randomized clinical trials. Archives of General Psychiatry, 59, 877-883.

Lang, P. J., \& Lazovik, A. D. (1963). Experimental desensitization of phobia. The Journal of Abnormal and Social Psychology, 66, 519-525.

LeDoux, J. E., Schiller, D., \& Cain, C. (2009). Emotional reaction and action: From threat processing to goal directed behavior. In M. S. Gazzaniga (Ed.), The cognitive neurosciences (4 ed., pp. 905-924). Cambridge, Massachusetts: The MIT Press.

Lees, J. (2009). Cognitive behaviour therapy and evidenced-based practice: Past, present and future. In R. House \& D. Loewenthal (Eds.), Against and for CBT: Towards a constructive dialogue? (pp. 77-85). Ross-on-wye: PCCS BOOKS

Lewis, C., Pearce, J., \& Bisson, J. I. (2012). Efficacy, costeffectiveness and acceptability of self-help interventions for anxiety disorders: Systematic review. British Journal of Psychiatry, 200, 15-21.

Lohr, J. M., Lilienfeld, S. O., \& Rosen, G. M. (2012). Anxiety and its treatment: Promoting science-based practice. Journal of Anxiety Disorders, 26, 719-727.

Mendlowicz, M. V., \& Stein, M. B. (2000). Quality of life in individuals with anxiety disorders. American Journal of Psychiatry, 157, 669-682. 
Mewton, L., Wong, N., \& Andrews, G. (2012). The effectiveness of internet cognitive behavioural therapy for generalized anxiety disorder in clinical practice. Depression and Anxiety, 29, 843-849.

Mojtabai, R., Olfson, M., Sampson, N. A., Jin, R., Druss, B., Wang, P. S., . . Kessler, R. C. (2011). Barriers to mental health treatment: results from the National Comorbidity Survey Replication. Psychological Medicine, 41, 1751-1761.

Mowrer, O. H. (1951). Two-factor learning theory: summary and comment. Psychological review, 58(5), 350-354.

Mowrer, O. H. (1956). Two-factor learning theory reconsidered, with special reference to secondary reinforcement and the concept of habit. Psychological Review, 63, 114-128.

Newby, J. M., Mackenzie, A., Williams, A. D., McIntyre, K., Watts, S., Wong, N., \& Andrews, G. (In press). Internet cognitive behavioural therapy for mixed anxiety and depression: a randomized controlled trial and evidence of effectiveness in primary care. Psychological Medicine,

Olatunji, B. O., Cisler, J. M., \& Tolin, D. F. (2007). Quality of life in the anxiety disorders: A meta-analytic review. Clinical Psychology Review, 27, 572-581.

Olatunji, B. O., Cisler, J. M., \& Tolin, D. F. (2010). A metaanalysis of the influence of comorbidity on treatment outcome in the anxiety disorders. Clinical Psychology Review, 30, 642-654.

Palmqvist, B., Carlbring, P., \& Andersson, G. (2007). Internetdelivered treatments with or without therapist input: does the therapist factor have implications for efficacy and cost? Expert Review of Pharmacoeconomics and Outcomes Research, 7, 291-297.

Parks, M. R., \& Roberts, L. D. (1998). 'Making MOOsic': The development of personal relationships on line and a comparison to their off-line counterparts. Journal of Social and Personal Relationships, 15, 517-537.

Patterson, W. M., Dohn, H. H., Bird, J., \& Patterson, G. A. (1983). Evaluation of suicidal patients: the SAD PERSONS scale. Psychosomatics, 24, 343-345, 348-349. 
Paxling, B., Almlov, J., Dahlin, M., Carlbring, P., Breitholtz, E., Eriksson, T., \& Andersson, G. (2011). Guided internetdelivered cognitive behavior therapy for generalized anxiety disorder: a randomized controlled trial.Cognitive Behaviour Therapy, 40, 159-173.

Preschl, B., Maercker, A., \& Wagner, B. (2011). The working alliance in a randomized controlled trial comparing online with face-to-face cognitive-behavioral therapy for depression. BMC Psychiatry, 11, 189.

Prins, M. A., Verhaak, P. F. M., Bensing, J. M., \& van der Meer, K. (2008). Health beliefs and perceived need for mental health care of anxiety and depression-The patients' perspective explored. Clinical Psychology Review, 28, 1038-1058.

Prins, M. A., Verhaak, P. F. M., van der Meer, K., Penninx, B. W. J. H., \& Bensing, J. M. (2009). Primary care patients with anxiety and depression: Need for care from the patient's perspective. Journal of Affective Disorders, 119, 163-171.

Rachman, S., Radomsky, A. S., \& Shafran, R. (2008). Safety behaviour: A reconsideration. Behaviour Research and Therapy, 46, 163-173.

Rachman, S., Shafran, R., Radomsky, A. S., \& Zysk, E. (2011). Reducing contamination by exposure plus safety behaviour. Journal of Behavior Therapy and Experimental Psychiatry, 42, 397-404.

Reger, M. A., \& Gahm, G. A. (2009). A meta-analysis of the effects of internet- and computer-based cognitive-behavioral treatments for anxiety. Journal of Clinical Psychology, 65, 53-75.

Rhebergen, D., Batelaan, N. M., de Graaf, R., Nolen, W. A., Spijker, J., Beekman, A. T. F., \& Pennix, B. W. J. H. (2011). The 7-year course of depression and anxiety in the general population. Acta Psychiatrica Scandinavica, 123, 297-306.

Richards, D. A., \& Borglin, G. (2011). Implementation of psychological therapies for anxiety and depression in routine practise: Two year prospective cohort study. Journal of affective disorders, 133, 51-60. 
Robinson, E., Titov, N., Andrews, G., McIntyre, K., Schwencke, G., \& Solley, K. (2010). Internet treatment for generalized anxiety disorder: a randomized controlled trial comparing clinician vs. technician assistance. PLoS ONE, 5(6), e10942.

Roy-Byrne, P., Craske, M. G., Sullivan, G., Rose, R. D., Edlund, M. J., Lang, A. J., . . . Stein, M. B. (2010). Delivery of evidence-based treatment for multiple anxiety disorders in primary care: a randomized controlled trial. Jof the American Medical Association, 303, 1921-1928.

Russel, L. B., Siegel, J. E., Daniels, N., Gold, M. R., Luce, B. R., \& Mandelblatt, J. S. (1996). Cost-effectiveness analysis as a guide to resource allocation in health: Role and limitations. In M. R. Gold, J. E. Siegel, L. B. Russel \& M. C. Weinstein (Eds.), Cost-effectiveness in health and medicine (pp. 3-24). New York: Oxford university press.

Ruwaard, J., Lange, A., Schrieken, B., Dolan, C. V., \& Emmelkamp, P. (2012). The effectiveness of online cognitive behavioral treatment in routine clinical practice. PLoS ONE, 7(7), e40089.

Salkovskis, P. M. (1991). The importance of behaviour in the maintenance of anxiety and panic: A cognitive account. Behavioural Psychotherapy, 19, 6-19.

Sandell, R., Böhm, T. (2006). Shall narrow-minded scientific view direct the choice of treatment of depression and anxiety? Skall inskränkt vetenskapssyn styra utbudet av behandling av depression och ångest?, Läkartidningen, 103, 562-563.

Santana, L., \& Fontenelle, L. F. (2011). A review of studies concerning treatment adherence of patients with anxiety disorders. Patient Preference and Adherence, 5, 427-439.

Seekles, W., van Straten, A., Beekman, A., van Marwijk, H., \& Cuijpers, P. (2011). Effectiveness of guided self-help for depression and anxiety disorders in primary care: A pragmatic randomized controlled trial. Psychiatry Research, 15, 113-120.

Shadish, W. R., Matt, G. E., Navarro, A. M., \& Phillips, G. (2000). The effects of psychological therapies under clinically representative conditions: a meta-analysis. Psychological Bulletin, 126, 512-529. 
Sherbourne, C. D., Sullivan, G., Craske, M. G., Roy-Byrne, P., Golinelli, D., Rose, R. D., . . . Stein, M. B. (2010).

Functioning and disability levels in primary care outpatients with one or more anxiety disorders. Psychological Medicine, 40, 2059-2068.

Smit, F., Cuijpers, P., Oostenbrink, J., Batelaan, N., de Graaf, R., \& Beekman, A. (2006). Costs of nine common mental disorders: Implications for curative and preventive psychiatry. Journal of Mental Health Policy and Economics, 9, 193-200.

Sobocki, P., Allgulander, C., Hillert, J., \& Jönsson, B. (2004). Hjärnsjukdomarnas kostnader i Sverige. Resultat från en europeisk studie. Läkartidningen(103), 1590-1594.

Spek, V., Cuijpers, P., Nyklicek, I., Riper, H., Keyzer, J., \& Pop, V. (2007). Internet-based cognitive behaviour therapy for symptoms of depression and anxiety: a meta-analysis. Psychological Medicine, 37, 319-328.

Statistics Sweden (SCB). (2011, 070912). Educational attainment of the population 2010. UF 37 SM 1101. Sveriges officiella statistik Statistiska meddelanden Retrieved 22 June, 2011, from:http:/www.scb.se/statistik/UF/UF0506/2010A01B/UF 0506_2010A01B_SM_UF37SM1101.pdf

Stein, M. B., Sherbourne, C. D., Craske, M. G., Means-Christensen, A., Bystritsky, A., Katon, W., . . Roy-Byrne, P. P. (2004). Quality of care for primary care patients with anxiety disorders. American Journal of Psychiatry, 161, 2230-2237.

Stewart, R. E., \& Chambless, D. L. (2009). Cognitive-Behavioral Therapy for Adult Anxiety Disorders in Clinical Practice: A Meta-Analysis of Effectiveness Studies. Journal of Consulting and Clinical Psychology, 77, 595-606.

Sucala, M., Schnur, J. B., Constantino, M. J., Miller, S. J., Brackman, E. H., \& Montgomery, G. H. (2012). The therapeutic relationship in e-therapy for mental health: A systematic review. Journal of Medical Internet Research, 14, e110.

Svanborg, P., \& Åsberg, M. (1994). A new self-rating scale for depression and anxiety states based on the Comprehensive Psychopathological Rating Scale. Acta Psychiatrica Scandinavica, 89, 21-28. 
Swedish Association of Local Authorities and Regions. (2013).

Internetbehandling. Implementering av internetbaserad KBT i hälso- och sjukvården., from:

http://webbutik.skl.se/bilder/artiklar/pdf/7164-952-2.pdf

Swedish Council of Health Technology Assessment [SBU]. (2005).

Behandling av ångestsyndrom, 1 , from

http://www.sbu.se/upload/Publikationer/Content0/1/angest

Vol_1.pdf

Swedish National Board of Health and Welfare [Socialstyrelsen].

(2010). Nationella riktlinjer för vård vid depression och

ångestsyndrom [National guidelines for depression and anxiety].

Titov, N., Andrews, G., Davies, M., McIntyre, K., Robinson, E., \&

Solley, K. (2010). Internet treatment for depression: a

randomized controlled trial comparing clinician vs.

technician assistance. PLoS ONE, 5(6), e10939.

Titov, N., Andrews, G., Johnston, L., Robinson, E., \& Spence, J.

(2010). Transdiagnostic Internet treatment for anxiety

disorders: A randomized controlled trial.Behaviour

Research and Therapy, 48, 890-899.

Titov, N., Andrews, G., Schwencke, G., Solley, K., Johnston, L., \&

Robinson, E. (2009). An RCT comparing effect of two types of support on severity of symptoms for people completing Internet-based cognitive behaviour therapy for social phobia. Australian and New Zealand Journal of Psychiatry, 43, 920-926.

Titov, N., Dear, B. F., Schwencke, G., Andrews, G., Johnston, L., Craske, M. G., \& McEvoy, P. (2011). Transdiagnostic internet treatment for anxiety and depression: a randomised controlled trial. Behaviour Research and Therapy, 49, 441452.

Ulvenes, P. G., Berggraf, L., Hoffart, A., Stiles, T. C., Svartberg, M., McCullough, L., \& Wampold, B. E. (2012). Different processes for different therapies: therapist actions, therapeutic bond, and outcome. Psychotherapy, 49, 291-302.

van Ingen, D. J., Freiheit, S. R., \& Vye, C. S. (2009). From the Lab to the Clinic: Effectiveness of cognitive-behavioral treatments for anxiety disorders. Professional Psychology: Research and Practice, 40, 69-74. 
Wampold, B. E., Mondin, G. W., Moody, M., Stich, F., Benson, K., \& Ahn, H. N. (1997). A meta-analysis of outcome studies comparing bona fide psychotherapies: Empirically, "all must have prizes". Psychological Bulletin, 122(3), 203-215.

Van Schaik, D. J. F., Klijn, A. F. J., Van Hout, H. P. J., Van Marwijk, H. W. J., Beekman, A. T. F., De Haan, M., \& Van Dyck, R. (2004). Patients' preferences in the treatment of depressive disorder in primary care. General Hospital Psychiatry, 26, 184-189.

Wang, P. S., Aguilar-Gaxiola, S., Alonso, J., Angermeyer, M. C., Borges, G., Bromet, E. J., . . Wells, J. E. (2007). Use of mental health services for anxiety, mood, and substance disorders in 17 countries in the WHO world mental health surveys. Lancet, 370, 841-850.

Weisberg, R. B., Dyck, I., Culpepper, L., \& Keller, M. B. (2007).

Psychiatric treatment in primary care patients with anxiety disorders: a comparison of care received from primary care providers and psychiatrists. American Journal of Psychiatry, 164, 276-282.

Vernmark, K., Lenndin, J., Bjarehed, J., Carlsson, M., Karlsson, J., Oberg, J., . . . Andersson, G. (2010). Internet administered guided self-help versus individualized e-mail therapy: A randomized trial of two versions of CBT for major depression. Behaviour Research and Therapy, 48, 368-376.

Wilamowska, Z. A., Thompson-Hollands, J., Fairholme, C. P., Ellard, K. K., Farchione, T. J., \& Barlow, D. H. (2010). Conceptual background, development, and preliminary data from the unified protocol for transdiagnostic treatment of emotional disorders. Depression and Anxiety, 27, 882-890.

Wittchen, H. U., \& Jacobi, F. (2005). Size and burden of mental disorders in Europe--a critical review and appraisal of 27 studies. European Neuropsychopharmacology, 15, 357-376.

Wittchen, H. U., Jacobi, F., Rehm, J., Gustavsson, A., Svensson, M., Jonsson, B., . . . Steinhausen, H. C. (2011). The size and burden of mental disorders and other disorders of the brain in Europe 2010. European Neuropsychopharmacology, 21, 655-679. 
World Health Organization (2001). The world Health report 2001: Mental health: New understanding, new hope. Geneva: World Health Organization.

Yuen, E. K., Goetter, E. M., Herbert, J. D., \& Forman, E. M. (2012). Challenges and Opportunities in Internet-Mediated Telemental Health. Professional Psychology-Research and Practice, 43, 1-8.

Öst, L. G. (1987). Applied relaxation: description of a coping technique and review of controlled studies. Behaviour Research and Therapy, 25(5), 397-409.

Öst, L. G. (2008). Cognitive behavior therapy for anxiety disorders: 40 years of progress. Nordic Journal of Psychiatry, 62 Suppl $47,5-10$. 


\section{ACKNOWLEDGEMENTS IN SWEDISH}

Det finns många människor att tacka som på olika sätt gjort denna avhandling möjlig. Alltid finns det någon jag glömmer att nämna, några vill jag särskilt lyfta fram, men till er alla berörda vill jag rikta ett stort tack!

Först och främst vill jag tacka alla deltagare, dessa modiga personer som utmanat sina rädslor och genomfört behandlingarna. De personer som rekommenderade sina patienter att söka till Studie III, trots att remissvar inte gick att få och randomisering gjorde att de inte visste om just deras patient fick vänta eller inte. Och sist men inte minst, "mina" psykolog och psykoterapeutstudenter som på ett föredömligt sätt intervjuat, behandlat och samlat in data. Ni tillsammans har på olika sätt bidragit till forskning som i förlängningen förhoppningsvis kan leda till en mer tillgänglig vård vid psykisk ohälsa.

Tack också till FORTE (FAS 2008-1145) för att ekonomiskt ha stöttat detta avhandlingsarbete.

Per Carlbring. Min huvudhandledare. Utan dig hade detta aldrig blivit av! Stort tack för att du trodde på mig och min akademiska förmåga och erbjöd den här möjligheten att förkovra mig i området (och få betalt för att läsa material jag ändå läser!) i min från början rent kliniska mission att erbjuda patienter adekvat och tillgänglig vård.

Gerhard Andersson. Min biträdande handledare. Tack för blixtsnabb respons då det behövts, för kloka råd i forskningsarbetet och för att du tydligt markerat att du fanns kvar efter Pers flytt från LiU.

Maria Tillfors. Granskare av avhandlingsarbetet vid två tillfällen. Din noggranna läsning och dina frågor har hjälpt mig att se arbetets för- och nackdelar. Stort tack för din hjälp i att förbereda mig inför det som är omöjligt att förbereda sig inför, en disputation.

Jonas. Min make, min älskade. Tack för att du inte försöker ändra mig utan låter mig vara precis såsom jag är. Och för att du i slutfa- 
sen av detta arbete la om ditt reseschema så att jag kunde arbeta dubbla skift. Utan dig hade det aldrig gått att både ha en familj, en hundvalp och en färdig avhandling! Jag älskar dig.

Siri och Hedda. Mina barn. Tack vare er tränar jag varje dag på att vara närvarande och uppleva det som händer precis just nu. Utan er hade jag fastnat inuti mitt eget huvud.

Min familj. Tack för att ni lyssnat och stöttat på alla upptänkliga sätt, för att ni uttryckt stolthet och intresse för mitt arbete, för att ni finns.

Maria Jannert. Utöver vän även kollega och en excellent klinisk handledare. Tack för att du behåller din övermänskliga förmåga att se det goda hos människor och se möjligheter i varje situation. Det behövs på en dystopisk cyniker som jag.

Malin Green Landell. Vän och före detta kollega. Tänk att det finns fler som vill prata forskning och ångest på fritiden. Tack för att jag får dela dina kloka reflektioner, vilken ynnest. Våra samtal gör mig skarpare.

Hugo Hesser. Som att ha en superintelligent, extralillebror. Med allt vad det innebär. Tack.

Erika Viklund, Clara Möller och Björn Philips. Mina kollegor och vänner från "the dark side of the force". Tack för alla roliga och stimulerande samtal, för er fantastiska humor och för att ni hjälper mig att vidga mina vyer. Ni gör mig glad.

Erik Hedman. Forskare vid KI och medarbetare i Studie III. Tack för att du likt en riddare i blå dunjacka hjälpte en dam (nåja) i nöd att förstå hälsoekonomins mysterier, och för att du också arbetar på tider som kan ses som udda.

Forskargruppen, alla inkluderade, med tillägg av bonusforskaren Rickard Östergren. Min hemmabas och forskartillhörighet. Tack för kaffestunder, korridorhäng, diskussioner och pepp när det behövts. 


\section{Empirical Studies}

The articles associated with this thesis have been removed for copyright reasons. For more details about these see:

http://urn.kb.se/resolve?urn=urn:nbn:se:liu:diva-100969 


\section{LINKÖPING STUDIES IN BEHAVIOURAL SCIENCE}

154. MUGISHA, INNOCENT SEBASAZA. Assessment and Study Strategies. A study among Rwandan Students in Higher Education. 2010. ISBN: 978-91-7393-340-7

155. ALM, FREDRIK. Uttryck på schemat och intryck i klassrummet. En studie av lektioner i skolor utan timplan. 2010. ISBN: 978-91-7393-322-3

156. LÖGDLUND, ULRIK. Networks and Nodes. Practices in Local Learning 2011. ISBN: 978-91-7393-249-3

157. SIN, SAMANTHA (AKA HSIU KALOTAY), An Investigation of Practitioners' and Students' Conceptions of Accounting Work. 2011. ISBN: 978-91-7393-174-8

158. BIRBERG THORNBERG, ULRIKA, Fats in Mind. Effects of Omega-3 Fatty Acids on Cognition and Behaviour in Childhood. 2011. ISBN: 97891-7393-164-9

159. KILHAMMAR, KARIN, Idén om medarbetarskap. En studie av en idés resa in i och genom två organisationer. 2011. ISBN: 978-91-7393-092-05

160. SARKOHI, ALI, Future Thinking and Depression. 2011. ISBN: 978-917393-020-8

161. LECH, BÖRJE, Consciousness about own and others' affects. 2012. ISBN:

978-91-7519-936-8

162. SOFIA JOHNSON FRANKENBERG, Caregiving Dilemmas: Ideology and Social Interaction in Tanzanian Family Life. 2012. ISBN: 978-917519-908-5

163. HALLQVIST, ANDERS, Work Transitions as Biographical Learning. Exploring the dynamics of job loss. 2012. ISBN: 978-91-7519-895-8

164. MUHIRWE, CHARLES KARORO, Developing Academic Literacies in Times of Change. Scaffolding Literacies Acquisition with the Curriculum and ICT in Rwandan Tertiary Education. 2012. ISBN: 97891-7519-841-5

165. RUTERANA, PIERRE CANISIUS, The Making of a Reading Society. Developing a Culture of Reading in Rwanda. 2012. ISBN: 978-91-7519840-8

166. SANDBERG, FREDRIK, Recognition of Prior Learning in Health Care. From a Caring Ideology and Power, to Communicative Action and Recognition. 2012. ISBN: 978-91-7519-814-9 
167. FÄGERSTAM, EMILIA, Space and Place. Perspectives on Outdoor Teaching and Learning. 2012. ISBN: 978-91-7519-813-2

168. FALKENSTRÖM, FREDRIK, The Capacity for Self-Observation in Psychotherapy. 2012. ISBN: 978-91-7519-797-5

169. BENNICH, MARIA, Kompetens och kompetensutveckling i omsorgsarbete. Synen på kompetens och lärande i äldreomsorgen - i spänningsfältet mellan samhälleliga förutsättningar och organisatoriska villkor. 2012. ISBN: 978-91-7519-777-7

170. RUSANGANWA, JOSEPH, Enhancing Physics Learning through Instruction, Technical Vocabulary and ICT. A Case of Higher Education in Rwanda. 2012. ISBN: 978-91-7519-739-5

171. MBABAZI, PENELOPE, Quality in Learning in Rwandan Higher Education: Different Stakeholders' Perceptions of Students' Learning and Employability. 2013. ISBN: 978-91-7519-682-4

172. BYSTRÖM, ERICA, Ett lärorikt arbete? Möjligheter och hinder för under-sköterskor att lära och utvecklas i sjukvårdsarbetet. 2013. ISBN:978-91-7519-679-4

173. KAGWESAGE, ANNE MARIE, Coping with Learning through a Foreign Language in Higher Education in Rwanda. 2013. ISBN: 978-917519-640-4

174. MUTWARASIBO, FAUSTIN, Understanding Group-based Learning in an Academic Context: Rwandan Students' Reflections on Collaborative Writing and Peer Assessment. 2013. ISBN: 978-91-7519-633-6

175. MÅRDH, SELINA. Cognitive erosion and its implications in Alzheimer's disease. 2013. ISBN: 978-91-7519-612-1

176. HARLIN, EVA-MARIE. Lärares reflektion och professionella utveckling - Med video som verktyg. 2013. ISBN: 978-91-7519-611-4

177. ÖSTERGREN, RICKARD. Mathematical Learning Disability. Cognitive Conditions, Development and Predictions. 2013. ISBN: 97891-7519-565-0

178. ENGVALL, MARGARETA. Handlingar i matematikklassrumet. En studie av undervisningsverksamheter på lågstadiet då räknemetoder för addition och subtraktion är i fokus. 2013. 978-91-7519-493-6

179. JOHANSSON, ROBERT. Treating depression and its comorbidity. From individualized Internet-delivered cognitive behavior therapy to affect-focused psychodynamic psychotherapy. 2013. ISBN: 978-917519-467-7 